\title{
AN INTEGRATED STUDY OF THE GRAYBURG/SAN ANDRES RESERVOIR, FOSTER AND SOUTH COWDEN FIELDS, ECTOR COUNTY TEXAS
}

\author{
Annual Technical Report \\ Reporting Period: 08/08/1996 to 07/31/1997 \\ Authors: Robert C. Trentham, DGS \\ Richard Weinbrandt, Ph.D.P.E. \\ William Robinson, M.S. \\ Report Issue Date: 10/23/1997 \\ DE-FC22-94BC14982--17 \\ Laguna Petroleum Corporation \\ 1003 N. Big Spring St. \\ P. O. Box 2758 \\ Midland, TX 79702
}




\section{Disclaimer}

This report was prepared as an account of work sponsored by an agency of the United States Government. Neither the United States Government nor any agency thereof, nor any of their employees, makes any warranty, express or implied, or assumes any legal liability or responsibility for the accuracy, completeness, or usefulness of any information, apparatus, product, or process disclosed, or represents that its use would not infringe privately owned rights. Reference herein to any specific commercial product, process, or service by trade

name, trademark, manufacturer, or otherwise does not necessarily constitute or imply its endorsement, recommendation, or favoring by the United States Government or any agency thereof. The views and opinions of authors expressed herein do not necessarily state or reflect those of the United States Government or any agency thereof. 
TABLE OF CONTENTS

EXECUTIVE SUMMARY

ABSTRACT V v

$\begin{array}{ll}\text { INTRODUCTION } & 1\end{array}$

$\begin{array}{ll}\text { GEOPHYSICS } & 1\end{array}$

SEISMIC PROJECT STATUS 2

PROJECT ORIENTATION

IMPORTANT REALIZATIONS 6

SEISMIC CORRELATION WITH GEOLOGY 6

$\begin{array}{ll}\text { SEISMIC INVERSION MODELING } & 7\end{array}$

INVERSION MODEL ANALYSIS 9

CONVERSION OF SEISMIC DATA TO ROCK PROPERTY DATA 11

$\begin{array}{ll}\text { SEISMIC CONCLUSIONS } & 13\end{array}$

GEOLOGIC OBJECTIVES $\quad 14$

CORE AND LOG DEVELOPED DEPOSITIONAL AND DIAGENETIC HISTORY OF THE GRAYBURG AND SAN ANDRES 14

$\begin{array}{ll}\text { FOSTER-11 CORE } & 15\end{array}$

$\begin{array}{ll}\text { FOSTER-11 LOGS } & 16\end{array}$

$\begin{array}{ll}\text { WITCHER-12 CORE } & 16\end{array}$

$\begin{array}{ll}\text { FOSTER-PEGUES-11 (FP-11) } & 16\end{array}$

$\begin{array}{ll}\text { WITCHER-2 DEEPENING } & 18\end{array}$

INTEGRATION OF GEOLOGIC RESULTS DERIVED FROM MODERN LOGS, CORE DESCRIPTIONS, CORE ANALYSES AND SEISMIC INTO A RESERVOIR MODEL

CORE K AND $\Phi$ FOR ALL CORES

WORK WITH TEAM MEMBERS TO IMPLEMENT A COMPLETION 
TECHNIQUE DESIGNED TO DOUBLE THE FRACTURE LENGTH IN THE LOWER GRAYBURG AND SAN ANDRES

WATER SATURATIONS

DEVELOPMENT OF A USABLE SEISMIC VELOCITY/LOG

POROSITY TRANSFORM

GEOLOGICAL/GEOPHYSICAL INTEGRATION

EVALUATION OF THE EFFECTIVENESS OF

RECENT COMPLETIONS UTILIZING WATER ANALYSES

GEOLOGICAL SUPPORT OF THE ENGINEERING AND GEOPHYSICAL EFFORTS AND PROVIDING A BRIDGE BETWEEN THESE TWO HISTORICALLY DISTANT DISCIPLINES

ENGINEERING

ENGINEERING OBJECTIVES

H.C. FOSTER-11

WITCHER-2

WITCHER-12

FOSTER-PEGUES-4

SIMULATION

COMPLETIONS AND PRODUCTION

PRODUCED WATER SUSPENDED SOLIDS SURVEY

DELAYS

TECH TRANSFER

REFERENCES 
FIGURES

LOCATION MAP AND STRATIGRAPHIC COLUMN

SEISMIC BASE MAP WITH WELL LOCATIONS, SEISMIC DATA GRID, AND LOCATION OF SEISMIC PROFILES

BASE MAP SHOWING LOCATION OF OPEN WELLBORES AVAILABLE IN AUGUST 1997

EXAMPLE OF WELL DATA SPREADSHEET 2

SEISMIC DATA PROFILE, DATA BANDWIDTH 10-110Hz 3A

SEISMIC DATA PROFILE, DATA BANDWIDTH 10-65Hz 3B

QUADRANT PHASE SHIFT DISPLAY OF SEISMIC DATA 4

SEISMIC PROFILE L-L'

SEISMIC PROFILE M-M'

SYNTHETIC SEISMOGRAM FORWARD MODEL

OF GRAYBURG ACROSS 3D PROJECT

SYNTHETIC SEISMOGRAM FORWARD MODEL

OF GRAYBURG POROSITY VARIATIONS

MAP OF TIME STRUCTURE TOP OF GRAYBURG 9

MAP OF TIME STRUCTURE OF LOWER PERMIAN 10

PROFILE L-L' FROM INVERSION MODEL DATA

WITH WELLS AND SONIC LOG CURVES 11

MAP OF THE THICKNESS OF GRAYBURG A ZONE 12

CROSS-PLOT OF POROSITY vS. INTERVAL VELOCITY OF GRAYBURG (SUBDIVIDED) A1 AND A2 ZONES

CROSS-PLOT OF POROSITY vS. INTERVAL VELOCITY OF GRAYBURG A ZONE USING ALL WELL DATA TYPES

CROSS-PLOT OF POROSITY VS. INTERVAL VELOCITY GRAYBURG A ZONE USING ONLY MODERN N/D LOG DATA SEISMIC INVERSION-DERIVED AVERAGE

INTERVAL VELOCITY FOR GRAYBURG A ZONE 
SEISMIC INVERSION-DERIVED GROSS AVERAGE POROSITY FOR GRAYBURG A ZONE

WH-12, FS-11, AND FP-11 NEUTRON/DENSITY CROSS-PLOT AND SONIC LOGS 16

DISTRIBUTION OF GRAINSTONE/PACKSTONE, WACKESTONE/MUDSTONE, AND ANHYDRITE UPPER 50' OF SAN ANDRES

WH-2 WATER SATURATION CALCULATIONS USING BOTH SONIC AND NEUTRON/DENSITY POROSITY

CROSS-PLOT OF POROSITY vs. PERMEABILITY USING ALL WELLS

CROSS-PLOT OF POROSITY vs. PERMEABILITY FP-11 WELL

FS-11 WATER SATURATION CALCULATIONS USING BOTH SONIC AND NEUTRON/DENSITY POROSITYDATA

CROSS-PLOT OF SONIC vs. NEUTRON DENSITY POROSITY IN FS-11 WELL. (A) UPPER GRAYBURG, (B) SAN ANDRES

ANALYSES OF PRODUCED WATERS FROM

RECENTLY COMPLETED WELLS

SECTION 36 PRODUCTION, 1986 TO PRESENT

TABLE 


\section{EXECUTIVE SUMMARY}

For a part of the Foster and South Cowden (Grayburg-San Andres) oil fields, improvement in oil production has been accomplished, in part, by using "pipeline fracturing" technology in the most recent completion to improve fluid flow rates, and filtration of waterflood injection water to preserve reservoir permeability. The 3D seismic survey acquired in conjunction with this DOE project has been used to calculate a 3D seismic inversion model, which has been analyzed to provide detailed maps of porosity within the productive upper 250 feet of the Grayburg Formation. Geologic data, particularly from logs and cores, have been combined with the geophysical interpretation and production history information to develop a model of the reservoir that defines estimations of remaining producible oil. The integrated result is greater than the sum of its parts, since no single data form adequately describes the reservoir. Each discipline relies upon computer software that runs on PC-type computers, allowing virtually any size company to affordably access the technology required to achieve similar results.

\section{ABSTRACT}

A project to recover economic amounts of oil from a very mature oil field is being conducted by Laguna Petroleum Corporation of Midland, Texas, with partial funding from a U. S. Department of Energy grant to study shallow carbonate rock reservoirs. The objectives of the project are to use modern engineering methods to optimize oil field management and to use geological and geophysical data to discover untapped potential within the petroleum reservoirs. The integration of data and techniques from these disciplines has yielded results greater than those achievable without their cooperation. The cost of successfully accomplishing these goals is to be low enough for even small independent operators to afford. This article is a report describing accomplishments for the fiscal year 1996-1997.

The accomplishments of the previous reporting periods are a foundation for the current results discussed in this report, and the continued monitoring of the effects of that work is part of the goals of the current Phase. During the Phase 1 period, field management was influenced by preliminary geological work done to define the distribution of porosity within the upper and lower parts of the Grayburg Formation and within the upper part of the San Andres Formation. Implementation of the field development recommendations made at the end of Phase 1 were based on an engineering simulation run using production history and geologic models. Oil production was doubled as a result of that work. Several wells were worked over and newly drilled wells contributed additional high quality subsurface core and log data. A "pipeline" fracturing technique, designed to double the induced fracture length over other methods, was used to improve fluid production by more effectively contacting the reservoir. Significant to the waterflood project was the improvement of injection water quality by system redesign. Monitoring the effect of using improved injection water continues. Water chemistry analyses, noting the difference of salinity of Grayburg fluids versus San Andres fluids, have been used to determine the 
reservoir origin of produced water, implicating San Andres water contamination of Grayburg production. Development of a produced and injected water chemistry database also continues.

The analyses of the seismic data have become a major factor in defining productive properties of the Grayburg reservoir. Seismic inversion is used to convert the seismic data to velocity traces, a form from which a quantitative evaluation of reservoir properties is extracted. Calibration of seismic-derived interval velocity attributes, using well log porosity information, enable mapping the distribution of porosity of the individual upper Grayburg zones comparable to production fluid flow zones. These detailed maps have modified the earlier reservoir description made from sparse subsurface data. This revised picture discloses reservoir compartments not recognized before, serves as a vital parameter in the revised engineering model of the reservoir, and modifies the influence of the production history and the original oil in place values. Future drilling will be guided by the new engineering model.

Initial seismic analyses targeted an understanding of the correlation basic geology and reservoir factors to seismic wiggle-trace data. Stratigraphy specific to a thick carbonate sequence with few internal seismic reflectors was examined, including a hands-on review of core to establish seismic-to-rock relationships. Consideration of the effect of rock properties, particularly porosity, on seismic data response, focused on those most important factors for continued study. Forward modeling was employed to visualize aspects of the geology with seismic reflection response, to exactly identify key geologic levels in the seismic data. Observations were made of the various seismic waveform attributes, but no strong correlations with important rock properties have been recognized. The studies of the seismic data, including inversion modeling, have been done entirely using inexpensive, but effective, PC-based seismic interpretation software well suited to analyzing 3D seismic data.

Melding new core and log data (products of Phase 1 recommendations) with preexisting data lead to the development of a better understanding of the depositional and diagenetic history of the Grayburg and San Andres Formations. Geologic log markers within the Grayburg represent low permeability zones that act as vertical barriers to fluid movement during oil production. Areas of reservoir with low porosity dolomite or anhydrite-filled dolomite result in poor production qualities and reduced water injection capacity. Also, core and log evaluation associate the top of the San Andres with a major karst event, and provide insight for a methodology to identify potential water producing intervals. Thus, the San Andres has been downgraded as a potential waterflood target.

The initial simulation model results, using seismic-derived porosity maps, fit within expectations, although some porosity modifications are being made. Continued well testing will provide data necessary for a more complete simulation. Team members worked closely to develop methodologies to bridge the distances among historically diverse scientific disciplines. 


\section{Introduction}

The objective of this two-phase study is to demonstrate an integrated methodology for reservoir characterization of shallow shelf carbonate reservoir that is feasible, and cost effective for the independent operator. Furthermore, it will provide one of the first public demonstrations of the enhancement of reservoir characterization using high-resolution three dimensional (3D) seismic data.

This particular project is evaluating the Grayburg and San Andres reservoirs in the Foster and South Cowden Fields, Ector County, Texas (Fig. A). This sixty eight (68) years old field was approaching its economic limit and the leases evaluated would have been abandoned in ten (10) years. A multi-disciplinary approach to waterflood design and implementation, along with the addition of reserves by selective infill drilling and deepening, is being applied to this field. This approach in reservoir development will be applicable to a wide range of shallow shelf carbonate reservoirs throughout the United States.

The first phase of the project included the design, acquisition, and interpretation of the 3D seismic survey, the collection and evaluation of geologic (core and log) data, and engineering (historical production, well test, injection) data from a variety of sources. From this work, a geologically based production history model was simulated. Based on the recommendations made at the end of Phase One, three new wells were drilled, one existing well was deepened, two wells were worked over, one TA'd well was reentered, and one well was converted to injection. In addition, the quality of the injection water was greatly improved, a step necessary prior to increasing injection in the project area. The realignment of the waterflood and all additional well work await the completion of the seismic based history match and engineering simulation.

\section{GEOPHYSICS}

A 3D seismic survey was acquired over three and one half square miles of this mature oil field for the ultimate purpose of mapping subsurface geologic parameters that affect oil production. The major guideline for interpretation is to establish a methodology for analyzing data and mapping significant criteria using state-of-the-art computer tools economically available to any company or individual.

Major steps in the development of the seismic project include:

* The purchase of PC computer-based seismic interpretation software well-suited to seismic data analysis and basic post-stak seismic data processing, and mapping software enabling adept integration of spreadsheet data from various sources

* Qualification of the seismic data set after minimal reprocessing of pre-stak traces to optimize frequency bandwidth, and to apply post-stak data phase correction

Preliminary examination of the stratigraphy specific to a thick carbonate rock 
sequence with few internal reflectors

* Forward modeling to visualize aspects of geology with seismic reflection response and to exactly identify key geologic levels in the seismic data

* Comparison of various seismic waveform attributes with well data to recognize possible statistical relationships

* Consideration of the affect of Rock Property factors, particularly porosity, on seismic data response, focusing on those most prospective factors for continued study

* Hands-on review of actual rock cores to get the geophysics into the rocks

* Development of a successful Seismic Inversion Model for use as a new data

* Calibration of seismic-derived interval velocity attributes using well log porosity information

* Mapping the distribution of porosity of the individual upper Grayburg zones from the seismic-derived data

* Incorporation of the heterogeneous distribution of porosity into production simulation models

Conceptually, two key ideas have been developed which guide the use of seismic data to assist production planning. First, determining quantitative map products based on seismic factors is necessary for input to engineering models, and second, the exact positions of thin geologic flow units must be determined in order to accurately relate seismic data to well and production data. These two interpretation requirements are complex, and are discussed throughout this report. The maps, which are of real use in this project, are not achieved by using conventional interpretation methods.

Seismic Project Status

The project underwent a change of geophysical interpreters in July 1996. William C. Robinson, geophysical consultant of Midland, Texas, joined the project.

The seismic project is being analyzed using the PC-based Vest 3DSEIS interpretation system. This software is most appropriate for stratigraphic interpretation of seismic data because the extensive set of tools within that package uniquely fit one project criterion of being economically available to independent oil companies and individuals. Supplementing the Vest system is the PC-based mapping and display software SURFER version 6.xx by Golden Software. This program is used to create superior quality maps of any geological and geophysical parameter and provides complete base map capabilities. The Workbench software can also import these maps. 
Base map construction was accomplished by editing pre-existing spreadsheet and CAD-type digital files using SURFER (Fig. 1). A master spreadsheet, recording surveyed well locations and extensive well top data, is used to post wells, including deviated holes. This file has been updated and added-to over time with new wells and new data columns. Culture data such as lease lines and roads reside in another spreadsheet. The spreadsheet definition here is basically that a row (across) of numbers or characters (representing a single well) consists of data values of location, well name, horizon depths, porosity values, production, etc., so that many wells create many rows and, thus, columns of values (Fig. 2). Geophysical spreadsheets contain three columns: two surface location coordinates and any other mappable parameter, such as depth, time, amplitude, velocity, etc. The master base map serves as a common base for all subsequent maps of geology, geophysics, and engineering.

In July 1996, the status of seismic interpretations was reviewed to determine steps to be taken for moving ahead. The seismic data (Fig. 3b) were reviewed to determine characteristics of bandwidth and phase. Using the Fourier analysis built into 3DSEIS, the bandwidth of the migrated stack data volume was determined to be sharply contained between $20-80 \mathrm{~Hz}$. Because the vibroseis sweep was $10-110 \mathrm{~Hz}$, the data process sequence was reviewed. Although the processes were generally appropriate and adequate, one filter parameter within the surface-consistent deconvolution steps had band limited the data initially to $20-80 \mathrm{~Hz}$. Tests indicated that the excluded amplitudes could not be recovered by additional spectral balancing of the data. The process sequence was re-run by Dawson Geophysical, except for the first deconvolution routine. The reprocessed data volume now contains a full-bandwidth wavelet which maximizes resolution, as a comparison of examples of both data sets indicates (Fig. 3a). The application of the spectral balancing process at critical places within the processing sequence is necessary to recover waveform amplitudes correctly and optimize the useful bandwidth. Monitoring bandwidth throughout the processing effort is essential.

Data phase was determined by comparing reflections at well tie locations with synthetic seismograms made using available sonic log digits. Digital log files in various formats were standardized to the GMA binary format for the master log library. Synthetic seismograms were made using zero-phase and "quadrant" phase-shifted wavelets of several bandwidths. Other displays using "octant" shifts (45 degrees) refine the matching process. Direct comparisons of zero-phase synthetic seismograms with sets of phase-shifted traces (Fig. 4) indicated that the data from the processor required a phase lead (between 90 and 180 degrees) to tie the zero-phase synthetic seismogram. Subsequently, optimum results from inversion modeling comparisons were achieved using data phase-shifted 135 degrees. Thus, the data volume was phase shifted, using the 3DSEIS phase shift routine, to produce a new data volume of zero phase data which has been used in subsequent analyses.

Synthetic seismograms were incorporated into a cross section and a 2D forward model was created to show ties of log correlations with seismic (and synthetic) reflections and 
demonstrate visual changes across the interpolated model. The results of this and other models are discussed later.

\section{Project Orientation}

A critical need for the re-development of basic relationships, both personal and dataassociated, was met twenty-one months after the project began, when the new geophysicist joined the staff. Familiarization with the project included a review of project location, various data available, existing previous work, association with team members and equipment, and project objectives. The importance of the meetings of team members is stressed since the integration of disciplines is essential to project success. Early discussions took place with team members, exposing their study objectives of relating geology, production history, and waterflood realignment program characteristics and their interest in the ability of the seismic data to detail those relationships between well control points. Examples of topics discussed were 1) relating the resolution of seismic reflection intervals to log fine-sequence resolution, 2) preliminary map observations compared statistically to zone porosity measurements and a test of the mechanical interface between geophysical and engineering computer software packages, 3) data resolution optimization, and 4) project plans and timing. Preliminary correlations were made for seismic reflections, simple and complex geometries of the Grayburg and San Andres were discussed, and an approximate vertical resolution of the seismic wavelet was estimated at $100 \mathrm{ft}$.

Attendance at a seminar sponsored by the University of Texas Lands and the Bureau of Economic Geology (November 6, 1996) provided insight for this project from the presented methodology. Work by the Bureau relates fine-cycle sedimentation packages in the South Cowden field to the seismic sequence. Recognition of geometries of various facies (tidal channels, bars or banks) will be a mapping objective in the Laguna project since rock properties associated with those facies strongly affect internal permeability and production flow.

The starting point of this stratigraphic study of seismic data was to take a quick look at basic reflection data attributes to observe obvious characteristics. Reflection changes occur within the Grayburg across the survey, indicating the formation is not homogeneous.

An early concern was the choices of geologic data to be targeted for comparison to seismic data. Statistics support the use of any parameters that will correlate as potentially assisting oil production. These factors typically include structural trap, seal and reservoir mapping. Structure in section is probably not a trapping factor, but laterally extensive intra-formation seals exist as fluid flow boundaries. These boundaries are identified as well log correlations. Reservoir heterogeneity is a major factor controlling oil production and waterflood effectiveness. Mapping porosity satisfies theoretical, observable, and practical requirements of the integrated study. Porosity can be quantified in many ways (net, phi-h, GAP, cut-off, etc.), so consideration of the seismic response and the end need for engineering model parameters has determined 
the use of Gross Average Porosity as the key parameter in this project.

Following suggestions from articles regarding use of seismic data to guide log property estimation (Schultz, Ronen, Hattori, and Corbett, 1995) and (Watts, Hinterlong, and Taylor), initial relationships between the seismic data and well data were sought. An early exercise was to compare the preliminary Grayburg reflection waveform attributes (such as instantaneous frequency and amplitude) over a short interval with Grayburg A1 zone average porosity, established from porosity-type log measurements in wells. The results were colorful and interesting, but geologically were weakly related, and served only to test the compatibility of seismic and well-derived data files with the engineering software. Because of those weak results, little importance was attached to the maps. It is now realized that these early maps did not even relate geologic zone positions correctly. This fact is mentioned because it is important to recognize errors in analysis as well as successes.

The objective at the early stage of any project is to make many observations efficaciously, creating profiles, cross sections, and maps. Deeper, time-consuming evaluations come later, once a degree of understanding and priority is established. The current study is limited to the Grayburg and San Andres formations, although maps of shallower and deeper formations have been made in order to recognize any significant geologic relationships. A list of logical maps of seismic reflections was initially established, including the Yates, Queen, lower Queen, Grayburg, San Andres, and some event immediately below the San Andres. These reflections were subsequently tracked on the seismic data and were mapped as surfaces of time structure, isochrons, and reflection amplitude. Subsurface (well) data from the spreadsheet were used to generate a series of contoured structure and isopach maps. These maps are used in the inversion model analyses and the production volume models.

Initial observations of the seismic data were focused on reflection character across the estimated time interval containing the Grayburg Formation. Synthetic seismograms placed geologic correlations (ranging from 40 - $140 \mathrm{ft}$ apart) at various positions within the sequence of reflections, falling near peaks, troughs, and zero-crossings (see synthetic models in Fig. 7). No consistent correlation criteria could be established because none exist. No reliable map of any geologic correlation within the Grayburg could be made using the seismic data because of the absence of those criteria.

A strong amplitude anomaly was noticed on the map of the amplitude of the seismic reflection initially attributed to the top of the San Andres. It was somewhat related to the presence of porosity (within the first $100 \mathrm{ft}$ of the San Andres sequence) in wells. The relationship compelled investigation as a useful indicator of porosity distribution. The initial reaction (from general experience) was that the existence of porosity near the top of San Andres should result in weaker reflection amplitude. However, utilizing the recent cores, the project geologist points out that there are no strong lithologic changes separating the Grayburg from the San Andres, so that only a weak San Andres reflection should exist normally. The reflectivity would potentially increase with porosity development. A forward model was made to test the effects of various amounts of 
upper San Andres porosity situations on seismic reflectivity, and the result compared well with the observed seismic amplitude increase.

\section{Important Realizations}

The seismic data do not respond as mappable reflection events to log correlations, not as peaks, not as troughs, and certainly not as zero-crossings. Peaks and troughs are the compound seismic response to impedance boundaries, but the zero crossing has no geological significance whatsoever. The fact is that seismic wiggle trace resolution, even optimized, is not adequate to map the detail of geology required for production model simulations. In fact, the rock characteristics are expected to vary so that any unique seismic criteria for a geologic marker would fail across the project. In addition, the quantitative (as opposed to qualitative or relative relationships) results needed to describe rock properties in absolute terms are not possible using reflection data. The course of study was set away from the wiggle trace data volume.

\section{Seismic Correlation with Geology}

Project personnel met to discuss the geology in general, to review well data, and to discuss well cores for the Foster-Pegues-11, the Foster-11, and the Witcher-12, wells drilled during Phase II of this project. This orientation with the laid out cores was of great benefit. Two-wall display, dip-oriented well log cross sections (L-L' and M-M') were constructed to demonstrate Grayburg and San Andres zone characteristics (Fig. 1). Two normal scale (10in/second) seismic profiles connecting the same well locations, several with sonic logs, show the seismic response across the zones and deep structural relationships not shown on logs (Fig. 5 and Fig. 6). These profiles, enlarged to 40in/second vertical scale ("zoomed" in), better show details of reflections associated with the Grayburg and San Andres. A companion cross section of synthetic seismograms enlarged to well log scale $(2.5 \mathrm{in} / 100 \mathrm{ft})$ helps to visualize vertical resolution relationships. A 2D forward interpolation model of the synthetic seismograms across the Grayburg sequence demonstrates some expected seismic changes across section L-L' (Fig. 7). Notably, the reflection tracked as the top of the Grayburg is closely associated with the A1 correlation in section 36, but diverges to tie to a lower Queen carbonate bed (separated from the Grayburg A1) in section 31. The strongest, most consistent seismic event cannot be used to locate the boundary of the first Grayburg fluid flow zone. Seismic profile M-M' duplicates the southern well log cross section map trace, also showing the seismic sequence from the Queen formation downward to the Pennsylvanian. Three strike-oriented seismic profiles have been built as arbitrary lines, but well log cross sections were not built to match them.

Synthetic models were created (Fig. 8) to demonstrate possible variations of porosity in the A1 and A2 zones within the top $120 \mathrm{ft}$ of the Grayburg formation. Except for basal quartz sand deposits less than $10 \mathrm{ft}$ thick at major inter-formation boundaries, the Grayburg lithology is dolomite and anhydrite. Reflections within the Grayburg most likely emanate from porosity contrasts. Model limits range from no porosity to extreme porosity. The responses likely to be observed in project well data are between $0 \%$ and 
$18 \%$.

Synthetic models were also created to demonstrate possible variations of porosity in the associated with the lower Grayburg and upper San Andres formations. Nine models varying the velocity of the lower $60 \mathrm{ft}$ of the Grayburg ( $\mathrm{G}$ and $\mathrm{H})$, and the first and second $50 \mathrm{ft}$ of the San Andres are arranged in panels of a wall display as a sort of matrix. The reflection responses of the models are compared to the reflections on the seismic wiggle-trace data to formulate an interpretation. It is important to recognize that the cause of a reflection associated with the top of the San Andres may take on different forms, depending on the rock properties above and below that horizon.

The first series of maps, discussed previously, includes subsurface and seismic reflection maps of main correlation horizons. All Grayburg internal correlations (log calls) were mapped as isopach intervals, both for quality control purposes and for their information value. The seismic reflection from near the top of the Grayburg (Fig. 9) was mapped, showing the features of the relatively flat shelf area in section 36 and the structural break to the outer shelf in section 31 .

Reflections from the lower Permian (Fig. 10), Pennsylvanian and Devonian were mapped to relate buried structure and (perhaps) faulting to the structural boundaries observed in the Grayburg sequence. Faults were tracked and may extend upward to the Grayburg; structure-associated paleotopography possibly affected some Grayburg and San Andres facies and diagenetic distributions.

Seismic Inversion Modeling

To satisfy the objective of mapping quantitative values related to reservoir porosity, derived from seismic data, seismic inversion modeling is used. Seismic inversion modeling is a method of converting processed seismic amplitude trace data (wiggle traces) into traces which resemble sonic log curves. In practice, it is a process of converting seismic amplitude data from sinusoidal traces containing a seismic wavelet to blocky, log-like traces with wavelet complexity removed. The ambiguities of the seismic wavelet (inadequate resolution and reflection interference) are removed from observations. The inverted traces are still represented in time, not depth. Density is not considered in the inversion process used in this study. The inversion model is computed using software within the Vest 3DSEIS system.

Where forward synthetic modeling attempts to predict seismic effect from a defined geology, inversion modeling attempts to calculate seismic (sonic?) velocity from seismic data. A human interpreter mentally incorporates knowledge from wells of the rocks and their distribution into a larger picture assisted by seismic data, essentially constraining the interpretation to the facts or reasonable fiction. Inversion modeling incorporates the facts of lithology-influenced data to create a more easily interpreted data set. Constrained inversion modeling input parameters consider: (1) tracked reflection horizons, (2) sonic log-derived velocity values, and (3) the interpreter's experience with the project geology to extend log-defined velocity limits. A range of velocity values is 
defined for each tracked reflection (an approximate lithology boundary) and for the total interval between tracked reflections. Provisions are made for other geological situations that may also occur. Seismic amplitude data to be modeled must be zero phase to provide geologically correct results. The inversion model result is very sensitive to data phase and can also be used effectively as a tool to refine phase correction. Model testing is an essential precursor to model building. Testing constraint parameters, amplitude factors, and comparing test models to well logs requires (well-spent) time.

A preliminary model was calculated for this project to specifically analyze the Grayburg and San Andres sequences. The model input parameters have been refined and expanded in the current model, but the results of the preliminary model are remarkable in the presentation of velocity-related characteristics of the seismic data. The inversion model is effective for the shelf area of section 36 of the seismic project, but the outer shelf geology in section 36 was not included in the following analyses because of inadequate constraint control in the preliminary model.

The seismic inversion model created in December 1996 produced a high correlation relationship of the inversion-derived average interval velocity cross-plotted with gross average porosity of the Grayburg A zone. The top of the A zone was defined by revising the reflection surface mapped as the Grayburg. The re-picking was done using the profile view of the inversion data, placing the pick at the low-to-high velocity interface (lower Queen - Grayburg). The 3DSEIS program allows tracking of non-amplitude data. The pick coincides with the top of the $A$ in section 36 , where the wells with rock property data are located. However, in section 31 , the $A 1$ is not the first carbonate below the lower Queen marker and does not coincide with top of the Grayburg. The study was not carried far into section 31. The bottom of the A interval was picked universally $10 \mathrm{~ms}$ below the A horizon, since the improved method had not then been developed.

Improving the inversion model itself involved testing other seismic parameter choices and more precisely identifying wavelet phase. Listed here are the user-input parameters that affect the inversion model and have been extensively tested:

Horizons - are located by tracking a peak or trough reflection associated with an impedance contrast definable in geologic terms to position velocity constraint values; modeling results show that the reflections may not coincide with lithologic boundaries

Velocity Constraints - are values of velocity determined from sonic logs, used to control inversion model trace values; minimum and maximum values set a range that represents geologic possibilities within each stratigraphic sequence being modeled

Amplitude - is a relationship of the processed seismic data with a synthetic seismogram

Bandwidth - is an approximation of wavelet bandwidth across the volume $(\mathrm{X}, \mathrm{Y}$, \& 
Time) of amplitude data to be inverted

Phase - is a variable that strongly affects the velocity values of the inversion trace and is a function of the input data rather than being a test parameter (see example on the preceding page)

Modifications to the preliminary inversion model input parameters involved varying the constraints of horizon position and velocity values. The lower Queen reflection is a consistent lithologic boundary and was retained. The "Grayburg" reflection is a composite reflection that does not resolve the top of the A zone, but is used to set the velocity at the top of the Grayburg sequence. The reflection near the San Andres may result from rock property changes near the interface since no continuous lithologic boundaries exist between the lower Grayburg and the San Andres. For this reason, the San Andres constraint is not handled as a lithologic boundary. Below the top of the San Andres constraint, values are needed, but reflections are discontinuous because of structural and stratigraphic complexity. The Holt, a carbonate unit in the lower San Andres, has been picked to constrain velocities within the San Andres.

Extensive testing preceded the calculation of a workable inversion model of section 36 , the area of virtually all well log-derived porosity control, and the area of the production history model. Constraint parameters were tested, varying a range of input items. The parameters used in the current model include basic reflection horizons of the lower Queen (-), the "near" top of Grayburg (+), the "near" top of San Andres (+), and the Holt lime. The original seismic wiggle data traces were phase-shifted 135 degrees to become zero-phase. The bandwidth defined for the model was $8-12-85-100 \mathrm{~Hz}$, slightly less than the optimum band but inclusive of traces in noisier areas.

Successful test model traces made in the testing have visually (qualitatively) good similarity to sonic logs in relative velocity curve shape and display resolution on the order of $50 \mathrm{ft}$ (Fig. 11). Progressive, small changes in successive model parameters were made to preserve the success of the preliminary model and to improve upon it. The objective of the optimized model is to have high cross-plot correlations of inversionderived velocity and wellbore-derived porosity for all productive zones.

Inversion Model Analysis

Definitions used in this report:

analysis boundaries - surfaces defined by log correlations, which may or may not be seismic reflection horizons, positioned in seismic time in order to isolate seismic characteristics for a very specific zone; they commonly cross changes in rock properties

zone - the rock volume, bounded by log correlations, to be compared to a volume of seismic data 
cross-plot - a graph showing the relationship of some seismic data property and a rock property (for example, seismic velocity vs. gross average porosity); a line of best fit is determined, the slope of which can be used to convert data from seismic property values into log property values

The primary geologic objective is to map the distribution of particular rock properties which can be used to describe fluid volume and fluid movement between wells over the long production history of the oil field, and to help predict future fluid behavior as a factor in engineering models for fluid flow simulation. Further objectives of the analysis are to find relationships of seismic data characteristics with rock properties, and to map the distribution of those properties for the studied geologic sequences. In order for these relationships to be meaningful, several factors must be resolved: (1) seismic characteristics of velocity must be accurately portrayed, (2) zones must be accurately defined, and (3) geologic properties under consideration must be represented in the seismic data. Seismic waveform attributes which are commonly discussed in the literature and are easy to produce were examined initially, but it has been concluded that their uses do not specifically meet the above criteria and provide only vague, empirical observations.

Qualification of test case inversion models for sonic velocity (geologic) accuracy addressed profile and map presentations. The profile views of inversion model traces (Fig. 11) are comparable with sonic logs (in time); where the inversion traces look like the sonic logs, the model is deemed successful. The map view of the average interval velocity within geologic zones is comparable with well log-derived rock property data, specifically, gross average porosity of those zones. The map analysis is more subjective than the profile analysis, but is ultimately the more important data product. The model used to create the current porosity distribution maps has good trace character and is associated with optimum velocity vs. porosity cross-plots for the A zone.

Accurate analysis of an inversion model for very specific geologic zones requires accurate positioning of zone boundaries in time in the seismic data. For this project, only the first of several zones of interest, the Grayburg A1, is defined by a seismic reflection event, and then only approximately because of limited resolution. The engineering model requirements demand the thinnest intervals possible to be measured and mapped. The thinnest mapped intervals of production are the Grayburg $A$, subdivided into $A 1(\sim 70 \mathrm{ft})$ and the $A 2(\sim 50 \mathrm{ft})$, the Grayburg B, subdivided into B1 ( 50 $\mathrm{ft})$ and the B2 $(\sim 50 \mathrm{ft})$, and the Grayburg $\mathrm{C}(\sim 30 \mathrm{ft})$. The lower Grayburg and the San Andres are also defined by zones of similar thickness. The inversion model describes vertical sequence intervals on the order of $5 \mathrm{~ms}(40-50 \mathrm{ft})$ thick, which might represent the true seismic resolution. If this conclusion is correct, analyses of those thin intervals are meaningful when applied to the flow unit thicknesses.

Establishment of analysis boundaries for the preliminary analysis was based on an interval of Grayburg A zone assumed to be $10 \mathrm{~ms}$ thick. This is a reasonable, but general estimate, which works in section 36 , but is not adequate just off structure in 
section 31 where that sequence thickens. In addition the $B$ and $C$ and the San Andres boundaries are not defined in any way by mappable seismic events and must be set some other way. A series of isopach maps (Figs. 12) was made from well data showing the thickness of the subdivided Grayburg zones. These maps have been used to predict an accurate position for each log correlation by converting thickness in feet to time in milliseconds. Summing the four Grayburg intervals that were calculated leads to creation of a San Andres time surface that is close to the reflection initially picked as the San Andres.

The development of analysis zone boundaries as seismic horizons also enabled an evaluation of several waveform attributes regarding their usefulness in responding to reservoir properties. Interval average slices were made for zones measuring instantaneous amplitude, instantaneous frequency, and instantaneous phase. Porosity data were cross-plotted with the interval average values for the A, B, C, and E zones. No clear relationships have been recognized in the cross-plots. The solution to analyzing the Grayburg geology does not lie in mapping the waveform attributes, at least not to the degree required for the engineering model.

A library of logs was compiled for easy access and review of zone boundaries and characteristics. Neutron source logs used for calibration of seismic maps show wellbore porosity characteristics, the manipulated values of which are listed on a spreadsheet. Sonic logs are also included with correlations marked. The integrated (in time) sonic logs are the source of interval velocity values used to convert the isopach maps to isochron maps.

\section{Conversion of Seismic Data to Rock Property Data}

Zones of the Grayburg (A, B, and C) were measured for average interval velocity from the inversion model. The interval averaging technique considers all samples (spaced one ms apart) between boundary horizon surfaces. The boundaries follow the time structure of the tracked horizons and are not time slices.

For carbonate rocks, rock velocity and rock porosity are related inversely; as porosity increases, interval velocity decreases. In this project seismic-derived average interval velocity is strongly related in the Grayburg A zone, moderately related in the B zone, and weakly related in the $\mathrm{C}$ zone, given the values of porosity calculated from calibration-quality well logs. No usable relationships are yet seen for the lower Grayburg or the San Andres, to be discussed later.

The values of porosity or any other rock property are in some sort of manipulated form. In order to relate to seismic data, these values must represent an adequately thick zone and the porosity parameter that is sensed as an acoustic impedance. Gross Average Porosity is an average of porosity for each foot of zone, no matter how thick the zone is. Clearly, thin zones will affect seismic response differently than thick zones having similar Gross Average Porosity. Data sets considering net feet of porosity commonly are subject to some minimum porosity cutoff value, and, again, total thickness can affect 
the seismic response. Porosity times height $(\mathrm{phiH})$ values consider thickness and are likely to affect seismic response in a consistent way. The upper Grayburg zones do not vary radically in thickness in section 36 , so that thickness-induced problems are minimal.

Quantitative comparison of inversion-derived velocity versus log-derived porosity is accomplished for each zone by cross plotting. The geologic parameter most useful to explaining historical production and advancing future development is rock porosity. The form of porosity most likely to be imaged by the seismic data in this project is Gross Average Porosity of a defined interval. The relationship of velocity and porosity is handled as a linear function, although, according to Schlumberger (Schlumberger Log Interpretation Charts) the relationship is slightly non-linear (Fig. 13). Porosity values used for calibration of maps are chosen strictly from neutron density logs. For several wells, values of porosity derived from a sonic tool and a neutron source tool were compared to show a difference in calculated porosity in dolomite, particularly where anhydrite is also present (Fig. 22). The difference in porosity determined from different log types, up to several porosity percent, is significant. Since the seismic data are being calibrated using log data, it is important to be consistent with log type. Continuing attention is also being paid to the possibility of detecting an anhydrite effect where converted porosity values are negative.

The cross-plot points determine the statistical best-fit relationship used to convert velocity to porosity (Fig. 13). The cross-plot graph displays the total Grayburg A zone, and, individually, the $A 1$ and $A 2$ zones. Velocity values for the $A 1$ are higher than for the total A interval, and velocity values for the A2 are lower. Theoretically, the seismic velocity value trend should be comparable for all zones, the difference in the distribution of points being related to porosity. Because the calculation of porosity is handled empirically, that is, the conversion relationship fits the data being used and may differ for each geologic zone, the conversion function is calibrated independently for each set of velocity vs. porosity points. A perfect seismic model should require only one curve preferably similar to the Schlumberger curve - to convert velocity data for any geologic zone.

The alignment of cross-plot points is of importance in determining the most reasonable linear fit. Determination of the slope function has been influenced by the slope of the Schlumberger relationship and knowledge of log data quality, weighing higher the better quality data. Thus, the statistical best-fit line calculated by the analysis program was not used. The expectations of converting interval velocity to porosity have been a point of lengthy discussion. Ultimately the successful comparison of two forms of data depends on the correctness and consistency of both.

The interval velocity was compared to the Gross Average Porosity values at included well points using the seismic-guided log analysis software in the Vest interpretation system. The comparison for all wells available with gross average porosity estimate has a poor relationship (Fig. 14a). It was recognized that the neutron-type logs, ranging in age from the 1950's to 1970's, lack the calibration consistency needed to 
measure porosity accurately and should not be used to calibrate seismic data as porosity data. When only wells with recent, calibrated neutron density logs were considered, the correlation of inversion-derived average interval velocity with Gross Average Porosity is reasonably good (Fig. 14b). Spreadsheet values of Gross Average Porosity in qualified wells range from less than $3 \%$ to more than $8 \%$, but the porosity in other, non-calibration wells likely exceed these limits. The "error", or scatter, of the points from the line that they determine, is within $1.5 \%$ typically with only a few points falling intolerably $(>2 \%)$ away from the line. The area around these wells may not be imaged perfectly by the seismic data or the calculated porosity values may have unrealized problems. Difference maps, commonly used to reduce mistie values inherent in the conversion process, are not used (so far) for this project.

The final step in mapping is to convert the inversion model-derived average interval velocity values (Fig. 15a) to porosity values (Fig. 15b) using the cross-plot line relationship. The conversion is handled automatically by the Vest 3DSEIS program, which uses either a linear recursion method to determine the fit of the line or, in the case here, a line determined by the user. Multiple curve (non-linear) relationships have been used for conversion, although the process is not so automatic. The calculated values of calibrated Gross Average Porosity are exported from the 3DSEIS program as a spreadsheet for plotting in Surfer as a map and as a spreadsheet for the production model. The process of incorporating the porosity distribution into the production model is under way and will be discussed in a future report. From initial observations, however, the porosity maps relate well to cumulative production in section 36 . High seismic-derived porosity in the northeast part of section 36 relates to the highest cumulative production in the section.

\section{Seismic Conclusions}

The values of porosity calculated for various zones in section 36 exceed the range of values in calibration wells, indicating that drilled wells do not represent the full range of porosity possibilities. Some seismic velocities convert to porosities of $14 \%$ (porous dolomite and possibly sandstone) while some convert to negative 2\% (anhydrite?), using a single line relationship. A multi-slope conversion curve will be used for future conversions to limit high porosity conversions to the range observed in wells in the highporosity area. The alignment of cross-plot points for the A1 and A2 zones is very organized; points in the B1 and B2 are less organized but still predict a reasonable porosity distribution. Cross-plots from the $\mathrm{C}$ zone and lower Grayburg do not graph reasonably and the reason for this poor result is not obvious. Results for the lower Grayburg and San Andres currently seem poor as cross-plots, a combination of unexpected inversion model character and limited calibration control. Further evaluation of the effectiveness of seismic-derived porosity maps will be made from qualifying production history models and, eventually, field operation choices.

Seismic Inversion Modeling is an effective process to convert seismic data from an ambiguous, non-unique form to a quasi-unique form controlled with lithologic constraints. The modeling itself is sensitive to reflection data variables, including 
processing, particularly stacking alignment, bandwidth-related scaling, and phase correction. The analysis of the model and its relation to rock property data are sensitive to the correct positioning of geologic zones in the seismic data volume and to the form that the subsurface data take. Although well data seem to set the standard for qualifying the accuracy of seismic results, the form that well data may take can be subjective and the quality of well data certainly can vary. Well data, on the near wellbore scale, may not be directly comparable to seismic data on its scale.

Vast amounts of oil remain in the ground in North America. Imaging of critical rock properties using seismic data will unlock much of that oil for production by helping to guide improved recovery.

\section{Geologic Objectives}

The geologic objectives of the past year were both typical of the daily routine of the exploitation geologist in any field, and creative in its necessity to expand the limits of "cooperative science" with other team members. Typical activities included:

* Melding the core and log data with existing data to develop a better depositional and diagenetic history of the Grayburg and San Andres

* The integration of geologic results of the one deepening and three new drills into the reservoir model derived from modern logs, core descriptions, core analyses and seismic

* Working with other team members to implement a completion technique designed to double the fracture length in the lower Grayburg and San Andres.

Some of the more atypical activities included:

* Continuing to develop a usable seismic velocity/log porosity transform

* Continuing the evaluation of effectiveness of recent completions utilizing water analyses

* Most importantly, supporting the engineering and geophysical efforts and providing a bridge between these two historically distant disciplines.

ĐodeSandAhdirgsDeveloped Depositional and Diagenetic History of the Grayburg

The existing core data available at the inception of the project was almost entirely from the upper Grayburg. The only cores still available were taken in the Witcher-6 (see Fig. $1 \mathrm{for}$ well and core locations) and are $177 \mathrm{ft}$ from the upper Grayburg and $60 \mathrm{ft}$ from the San Andres. As a result of the preliminary simulation completed at the end of Phase One of the study, however, it was realized that the lower Grayburg is a virtually 
undeveloped reservoir and the San Andres had significant remaining untapped oil in place. These two reservoirs were the least understood. The drilling program implemented in Phase Two included the recovery of core from both the lower Grayburg and the San Andres in order to better understand these reservoirs.

Foster-11 (FS-11) Core

The Foster-11 was cored in the lower Grayburg from 4045 - $4148 \mathrm{ft}$ and the San Andres cored from $4149-4220 \mathrm{ft}\left(\right.$ see Note $\left.^{1}\right)$. The core analysis indicates that the lowermost Grayburg is relatively tight. The San Andres core analyses from the Foster-11, are consistent with the two San Andres cores (Witcher-6, and Brock-10) taken prior to the study.

The lower Grayburg dolomite was found to consist of a series of shallowing upward cycles composed primarily of shallow subtidal to intertidal to supratidal facies. The visible porosity is primarily fenestral with little if any secondary porosity. There are some small, 2-4 ft long vertical fractures with oil staining. The deepest water facies (Maximum Flooding Surface), a fusulinacean wackestone, are found within $30 \mathrm{ft}$ of the transgressive base of the Grayburg. There are some fine grained siliciclastic which have percolated down into the karst associated with terminal San Andres event and at the base of the Grayburg. A number of exposure surfaces with associated minor karstification are seen in this section.

The San Andres is composed of very porous and permeable cross-bedded ooid and skeletal packstones and grainstones separated by intervals of massive anhydrite with collapsed mudstone and wackestone rubble. These anhydritic intervals are interpreted to be cavern fill sediments as they are featureless and lack the classic "chicken wire texture" of sabkha anhydrite. The terminal event of the San Andres is a major subaerial exposure surface with an associated drop in the water table of at least $60 \mathrm{ft}$ at the Foster-11 location (Fig.16), and $50 \mathrm{ft}$ at the Witcher-2 location (the Witcher-2 is structurally lower and basinward of the Foster-11). During subaerial exposure a sequence of mudstones and wackestones, originally interbedded with the grainstones and packstones, underwent intense dissolution. The aragonitic mudstones and wackestones were prone to dissolution by fresh water in the vadose environment, whereas the calcite rich grainstones and packstones were resistant and acted as cave roofs and floors. There is crackle breccia, indicative of incipient cave roof collapse, in

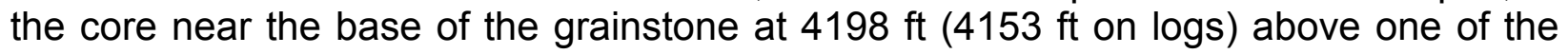
anhydrite infill intervals.

Note: Because of a driller's error, the core depths were $45 \mathrm{ft}$ off from the electric log depths. Thus $4200 \mathrm{ft}$ in the core equals $4155 \mathrm{ft}$ in the electric log. Core depths referred to in this report are adjusted. The core analyses report, however, reflects the depths as recorded at the well site. 
There are no area-wide log correlations in the upper $150 \mathrm{ft}$ of the San Andres. From the core/log relationships, the lithology ranges from $100 \%$ anhydrite: to $50 \%$ wackestone/ mudstone or anhydrite and 50\% grainstone/packstone: to almost $100 \%$ grainstone/packstone (Fig.17). Beginning $50-75 \mathrm{ft}$ below the top of the San Andres, and extending down at least $150 \mathrm{ft}$, there is a to be a series of $30-70 \mathrm{ft}$ thick shallowing upward sequences, which shallow into thick, highly porous units (interpreted to be grainstone shoals), capped by less porous units (interpreted to be lower energy packstone/wackestone). These units are identified by a porous log signature, as there is little gamma log character. When these facies were plotted on a map of seismic reflection amplitudes at the top of the San Andres, a good correlation was seen. Anhydrite-rich log character is correlated with low reflection amplitude, and grainstone/packstone ( $>8 \%$ porosity) log character with high reflection amplitude.

Witcher-12 (WH-12) Core

The Witcher-12 (Fig.17) was cored in the lower Grayburg from 4190 - $4225 \mathrm{ft}$ and the San Andres cored from 4226 - $4369 \mathrm{ft}$, with full recovery. A review of the core indicated the San Andres interval has excellent oil shows and fluorescence. There are three main intervals with porosity and shows. The deepest zone (4341- $4355 \mathrm{ft})$ is an interval of leached fusulinacean wackestone to packstone with bleeding oil. The interval has $9 \mathrm{ft}$ of greater than $9.5 \%$ porosity, with permeabilities ranging from 0.67 to $5.01 \mathrm{mD}$. This zone also appears to have excellent porosity $(12 \%$ to $16 \%)$ on the neutron/density cross-plot. The middle zone (4316-4332 ft) is a fine-grained skeletal packstone to grainstone with excellent oil stain; it has $18 \mathrm{ft}$ of greater than $8.4 \%$ porosity, with permeabilities ranging from 0.78 to $14.74 \mathrm{mD}$ with most in the range of $2.5 \mathrm{mD}-5.0 \mathrm{mD}$. The upper porous zone in the San Andres (4268-4302 ft) is an oil-stained, mottled, cross-bedded, skeletal packstone with fractures bleeding oil. Within the upper porosity zone $(4273-4312 \mathrm{ft}$ ) there is $11 \mathrm{ft}$ of greater than $7.7 \%$ porosity. The permeabilities, however, range from only $0.7-1.3 \mathrm{mD}$.

The lower Grayburg, as in the FS-11, is a series of shallowing upward cycles composed primarily of shallow subtidal to intertidal to supratidal facies. The visible porosity is primarily fenestral with little if any secondary porosity. The deepest water facies (associated with Maximum Flooding Surface), a fusulinacean wackestone, are also found within $30 \mathrm{ft}$ of the transgressive base of the Grayburg. There are only minor, finegrained siliciclastics at the base of the Grayburg. A number of exposure surfaces with associated minor karstification are seen in this section.

Foster-Pegues-11 (FP-11)

The full description of the core was discussed in the 1995-1996 annual report. One hundred and twenty feet (120 ft) of core were recovered from the lower Grayburg in the Foster-Pegues-11 (FP-11). The cored interval began in the lower "B" zone (basal upper Grayburg) and included the "C", "D", "E", and part of the "F" zones of the lower Grayburg. 
The purpose of coring this interval was to gain information on the lower Grayburg, which the reservoir simulation had identified as having significant untapped reserves.

The interval is composed primarily of shallow subtidal to supratidal shallowing upward carbonate sequences with minor anhydrite. There is a significant interval with tidal flat "Teepee Structures" in the "D" zone, and evidence of at least $34 \mathrm{ft}$ of subaerial exposure in the " $\mathrm{C}$ " zone. Capping the " $\mathrm{C}$ " zone is a red to gray terrigenous sand that transgressed the top of the lower Grayburg subaerial exposure surface. This surface and the associated karstification have also been identified, over 60 miles to the northwest, in the Eunice Monument South (Grayburg) Field on the west side of the Central Basin platform in Lea County, New Mexico, where it also represents the boundary between the upper and lower Grayburg (R. Lindsay, personal communication).

One of the main questions raised in reviewing the initial simulation results was "why is the San Andres not as productive as expected?" The San Andres is productive in both the Foster and South Cowden Fields where it has had a variable production history. Two wells, the Foster-11 and Witcher-12, were cored across the San Andres/ Grayburg in order to provide a better understanding of the stratigraphic boundary and how it controls production. The upper San Andres in the study area is composed of a series of cross-bedded ooid, fusulinacean, and skeletal grainstone and packstone shoals capped by thin-bedded wackestone and mudstone intervals. The cores reveal a terminal San Andres subaerial exposure event that created facies specific cavernous porosity which was later the site of massive anhydrite and/or shale filling. The mudstone and wackestone intervals appear to have been prone to dissolution, while the grainstone and packstone rich intervals were resistant to dissolution and formed cave floors and roofs. The paleo water table in the study area appears to be $50-70 \mathrm{ft}$ below the top of San Andres based on the change from vertical vadose to horizontal phreatic features. There is no correlatable clastic unit at the top of the San Andres, nor are there internal markers to aid correlations.

Based on the core description, the San Andres on logs was divided into three facies packages: high-energy grainstone/packstone, low energy mudstone/ wackestone, and anhydrite dominated diagenetic. The San Andres was then divided into $50 \mathrm{ft}$ thick intervals based on the recognition of the paleo water table $50 \mathrm{ft}$ below the top of San Andres, and a thin, discontinuous marker at $+/-100 \mathrm{ft}$ below the San Andres top, which coincides with the base of observed fresh water diagenesis. In the uppermost $50 \mathrm{ft}$, a grainstone to packstone shoal, was developed at a break in slope on the shelf, and on the windward flanks of low relief paleo-highs (Fig.17). The low energy mudstone/wackestone facies and areas of anhydrite diagenesis were found in the more protected lagoonal area. The interval $50-100 \mathrm{ft}$ below the top of San Andres also shows depositional facies distributed relative to paleo-structure. There is significantly less anhydrite, however, as the bulk of this interval was below the water table during exposure.

The San Andres/Grayburg boundary is both a barrier to oil migration and associated with a seismic reflector despite its lack of a paleosol or clastic rubble. Total dissolved 
solids in the San Andres waters are 50\% higher than in Grayburg waters, and reservoir pressures are significantly different. Core analyses from the San Andres indicate a high percentage of secondary porosity, which is confirmed by sonic/neutron-density crossplot log analysis. The down dip extent of this exposure surface is unknown. Log correlation of the vadose interval as a depositional sequence would result in misinterpreting the truncated San Andres in tectonically active areas. An understanding of the importance of diagenesis in the San Andres reservoir is critical in successful well completions.

\section{Witcher-2 (WH-2) Deepening}

Based on log character (Fig. 18), the upper $21 \mathrm{ft}$ of the San Andres is composed of a 2 $\mathrm{ft}$ thick massive anhydrite, an $11 \mathrm{ft}$ thick shale rich cave infill and a $7 \mathrm{ft}$ thick massive anhydrite, above a porous (16\% cross-plot porosity) interval with possible fractures (crackle breccia?). At the base of the porous unit, and just above the interpreted water table, is another anhydrite interval. As in the Foster-11, the porous interval is believed to be calcite rich grainstone/packstone. This diagenetic overprint on the uppermost San Andres has a major impact on reservoir distribution and behavior. Without a proper understanding of this diagenetic history, successful completions in the San Andres are "hit or miss". The Witcher-2 was completed flowing from acidized perfs in the upper $60 \mathrm{ft}$ of the San Andres in an area with high seismic reflection amplitude.

Integration of Geologic Results Derived from Modern Logs, Core Descriptions, Core Analyses and Seismic into A Reservoir Model to be input into the Simulator

\section{Core $\mathrm{K}$ and $\Phi$ for All Cores}

During the simulation, a question arose regarding the permeability and porosity of the different layers used in the model. Although six wells were cored (Fig. 1) in sections 36, 31 , and 32 (just to the east of section 31), only the cores taken in the Sun Witcher-6 still exist. The Sun Witcher- 6 was cored in the upper Grayburg and San Andres. The Arco Brock-10 was cored in the San Andres. The Arco Foster-Pegues-3-X was cored in the upper Grayburg. The General American Maurice-7 was cored in the upper Grayburg. The Great Western Johnson-19 was cored in the upper and lower Grayburg. The Richmond Drilling Maurice-3-A was cored in the upper Grayburg. Recovered was a total of $950 \mathrm{ft}$ of upper Grayburg, $40 \mathrm{ft}$ of lower Grayburg, and $115 \mathrm{ft}$ of San Andres. Unfortunately, the Witcher- 6 core only covers upper Grayburg and a portion of the San Andres and does not adequately describe the entire reservoir. The recovery of cores in three new drills, the Foster-Pegues-11 (lower Grayburg), Foster-11 (lower Grayburg and San Andres), and the Witcher-12 (lower Grayburg and San Andres) provides a framework to better describe the entire reservoir.

A closer examination of the $\Phi$ vs. K was undertaken and a series of plots was generated using the core reports from the existing, and recently recovered cores. The "All Wells All " plot (Fig. 19) of $\Phi$ vs. K contains analyses from all the cored wells. The wide scatter of data initially appears to show no distinct trend. However, there are three distinct 
populations: a high permeability/low porosity "fracture field", a low permeability/high porosity "secondary" or "vugular field", and a permeability/porosity field which exhibits a "normal" distribution for shallow shelf carbonates.

The fracture field is present in the Grayburg Formation in the Witcher-6, Johnson-19, Maurice-7, and Foster-Pegues-3X. In each well, there are a limited number of values (23 ) indicating that fractures make only a minor contribution. In addition, there are two 4 - 5 $\mathrm{ft}$ thick intervals in the core taken from the Foster-Pegues-11 with oil staining in fractures. The log analysis indicates that these zones have less than 3\% porosity and would not have been perforated without the core data. "Chatter" on the sonic log is evident in those intervals with fracture porosity in core, and can be used to predict fractured intervals on logs.

The "secondary" porosity field is composed of San Andres in the Brock-10 and Witcher-6, and some upper Grayburg in the Maurice-7. The San Andres in the Witcher-6 core is composed of clean, high-energy grainstones and packstones with secondary interparticle porosity.

Analyses from the Brock-10, Foster-11, Witcher-12, and Witcher-6 indicate that the San Andres reservoir is a poor water flood candidate. Although the logs and cores indicate zones with $18-20 \%$ porosity, the low permeability (averaging $1 \mathrm{mD}$ at $10 \% \Phi$ ) would preclude successful waterflooding on 20 acre spacing, and raise the risk of successfully waterflooding on 10 acres. This conclusion is supported by the marginal results in a San Andres water flood project west of the study area.

Few Grayburg analyses fall in the secondary porosity range, leading to the conclusion that most of the upper Grayburg reservoir is composed of connected interparticle (primary) porosity with good permeability. Those analyses that do plot in the secondary field are believed to represent leached grainstone shoals. The analysis of the FosterPegues-11, the first lower Grayburg new drill, shows the cored, lower Grayburg in this well to have a large component of primarily tight dolomite with less than $4 \%$ porosity and less than $0.2 \mathrm{mD}$ of permeability, and a small component of "Secondary Porosity" with porosity $3-6 \%$ and permeabilities of $0.3 \mathrm{mD}$. The best log porosity, however, in the "G" and " $\mathrm{H}$ " zones was entirely below the cored interval (The " $\mathrm{G}$ " and " $\mathrm{H}$ " zones were cored in the $\mathrm{WH}-12$ and $\mathrm{FS}-11$ ). There is a significant component of fracture porosity (less than $3 \%$ porosity but up to $20 \mathrm{mD}$ of permeability) in the "C" and "E" intervals. The fractures in the " $\mathrm{C}$ " are proposed as the explanation for the behavior of the Foster-1WI after clean out. The well had been injecting into the "A" zones only and was cleaned out through the lower Grayburg. When injection resumed, the well took up to 200 BWPD, initially on vacuum, with $85 \%$ of the injection water entering the "C" zone.

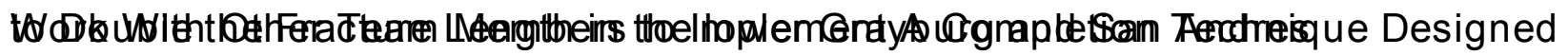

The San Andres in the Witcher-12 (Fig. 16) was evaluated and tested during the first quarter 1997. Because of the time required to complete whole core analysis, it was 
decided to perforate and acidize the upper two zones in the San Andres to determine their potential producibility based on visual inspection of the core and log analysis. Initially, the upper two porous zones in the San Andres were perforated and acid spotted. On swab test the zones had very slow fluid entry and only about $10 \%$ oil cut (see ENGINEERING).

The results of the acid stimulation of these two zones were later confirmed by the core analyses. The upper zone has very low permeabilities due to anhydrite infilling and would require additional stimulation. Although the middle zone has better permeabilities, the geologic model proposed for the upper San Andres assumes significant areal variability and, therefore, the core permeabilities may not be representative of the zone away from the well bore. The hypothesis is that subaerial exposure and fresh water diagenesis has significantly altered the San Andres reservoir. Evaluation of the slabbed core indicated the presence of fresh water diagenesis as deep as $95 \mathrm{ft}$ below the top of San Andres. There are intervals with mudstone and wackestone collapse breccias encased in cavern-fill, massive anhydrite. These are interbedded with porous grainstone and packstone intervals (the tested intervals), with only minor dissolution but variable anhydrite infill. Other cavernous intervals are filled with very fine sand and silt that percolated down, and partially filled, solution enlarged vertical fractures in the vadose zone.

Log analysis would typically lead to the conclusion that both of the tested intervals should be productive. Since neither zone is commercially productive without fracture stimulation, the large amount of secondary porosity cannot be contacted without significant effort following the development of a better understanding of the reservoir. Although the porous grainstone and packstone intervals locally have excellent porosity and permeability, they have become compartmentalized during fresh water diagenesis, shale infiltration during exposure, and later anhydrite pore-infilling during burial, which reduced overall permeability.

\section{Water Saturations}

Water saturations (Sw's) for the San Andres, in the Foster-11 (Fig. 21), calculated using neutron/density cross-plot porosity appear to be too optimistic $(9-20 \% \mathrm{Sw})$ when compared with visual inspection of the core and the production history of other wells in the area. When water saturations for the same interval are calculated using sonic porosity, some zones calculate to have higher, and more realistic, saturations (34-46\% $\mathrm{Sw})$, while other zones calculate "wet" (50-100\% Sw). When two zones with cross-plot porosities of $14-18 \%$ and low Sw's (calculated by both methods) were perforated and acidized, pumping production rates of only $4-5$ BO and 6-8 BWPD were obtained.

A possible explanation for these results is found in the porosity/permeability cross-plots of the core data. Although many analyzed intervals have permeabilities of $>1 \mathrm{mD}$ for porosities of $14-18 \%$, other highly porous zones have permeabilities of $<1 \mathrm{mD}$. A comparison of the cross-plot neutron/density porosity (which match well with the core analyses), to the sonic porosity is revealing. There appears to be $8-10 \%$ secondary 
porosity above the sonic porosity (Fig. 22). Zones with up to $18 \%$ total porosity may have only $5-7 \%$ sonic (primary interconnected) porosity and low permeabilities $(<1 \mathrm{mD})$. This observation coupled with the production test results indicates that there is a dual porosity system in the San Andres. One system is porous but not very permeable (vuggy), and the other is permeable and porous (interparticle connected). The San Andres had been fractured and tested in the FS-11 but because the frac treatment was below the oil/water contact, the large volume of water produced precluded an accurate assessment of the San Andres production capacity.

The Witcher-2 was deepened from the upper Grayburg through the lower Grayburg and the San Andres to contact reservoir not previously productive at this area. Again, as in the Foster-11, Sw calculations using neutron-density cross-plot porosities are overly optimistic (Fig. 18). Water saturations calculated using sonic porosities were more variable and more realistic. A lower zone, 4388-4398 ft, was perfed and acidized based on fair mud log shows and marginal cross-plot water saturations (16-45\%). This zone flowed $100 \%$ water, confirming the sonic derived water saturations $(55-100 \%)$ were correct. The zone from 4290 - $4315 \mathrm{ft}$ had cross-plot porosities of $9-13 \%$ and sonic derived water saturations of from $12-45 \%$. Upon completion, the San Andres produced $3500 \mathrm{BO}$ and $13500 \mathrm{BW}$ in less than 6 months. There appears to be the dual porosity system present in this interval as the water production initially dropped at a faster rate than the oil production. The oil production declined at a rapid rate to $4-5 \mathrm{BO}$ and 30 BW and the San Andres was abandoned after producing for only 6 months. The $\mathrm{WH}-2$ well was recompleted in the lower Grayburg and has produced, through the end of August 1997, 11,850 BO, and 1,777 MCF in 6 months.

\section{Development of A Usable Seismic Velocity/Log Porosity Transform}

\section{Geological/Geophysical Integration}

A considerable amount of time has been spent working closely with the Project Geophysicist, in an effort to combine the geologic model with the seismic interpretation. The geologic model consists of a high-energy packstone/grainstone-dominated San Andres with an exposed, eroded and karsted top, a tidal flat dominated lower Grayburg with multiple small exposure surfaces, and a high stand dominated upper Grayburg with laterally extensive grainstone/packstone shoals. This triad also reflects the variable production history with the upper Grayburg being a mature field with a poorly designed waterflood, an undeveloped lower Grayburg with essentially virgin pressures, and the San Andres with a varied production history and multiple oil/water relationships.

For the seismic inversion model to be successful, it is essential that the geological zones be properly identified within the seismic data. The first "problem" was identifying the A1 Zone top, as well as the Grayburg top, and delineating the "Lowstand Wedge" of sediments that is present between the A1 and Grayburg in the east part of the survey. If the wedge zone, which is predominantly low velocity, were included in the A1 zone, the inversion would be incorrectly interpreted. This error would then have been carried down through the section. This "wedge zone", which appears to thicken to the east and 
south, may equate to part of the Grayburg 4 sequence identified in the South Cowden Field Study (Ruppel and Lucia, 1996).

A second problem is on the cross-plot of the "total gross porosity" from logs and the seismic velocity (Fig. 14a). It was noted that the smallest error bars were associated with the most modern logs. Those wells where both neutron and density are the best fit to the velocity in the A1 and A2 zones. Although there is less secondary porosity in the Grayburg than in the San Andres, where the cross-plot neutron/density porosity is typically twice the sonic porosity, sonic or density logs alone under-report the gross interval porosity.

The integrated geological/geophysical effort developed a usable seismic velocity/log porosity transform for each Grayburg producing interval. To develop confidence in the porosity log/seismic velocity transform, however, it is necessary to understand how the mineralogical and textural variations in the reservoir impact the transform. As noted previously, in the core analyses there are different porosity/permeability $(\varnothing / \mathrm{k})$ transforms for intervals with "primary" porosity only and predominantly "secondary" porosity, (Fig. 19). In intervals where sonic and neutron/density cross-plot (NDXP) porosity exhibit little separation, core $\Phi / \mathrm{k}$ plot within the "primary" porosity field. This relationship exists in the lower Grayburg and in the upper Grayburg where grainstone shoals are not present. For intervals where sonic and NDXP porosity show significant $(>2 \%)$ separation, core $\Phi / k$ plot within the "secondary" porosity field. This relationship exists in the San Andres and in the grainstone shoals in the upper Grayburg.

Visual inspection of the porosity suite, plotted on a single log, and the equivalent core $\Phi / \mathrm{k}$, led to the belief that the primary and secondary "porosity regions" have different slope relationships. In intervals with significant secondary porosity, an estimated $2 / 3 \%$ increase in secondary porosity for every $1 \%$ increase in total log porosity seemed to fit, above $6 \%$ porosity, (Fig. 22). For example, at $18 \%$ total porosity (from the NDXP), an estimate of $8 \%$ secondary $(2 / 3 \times(18-6))$ and $10 \%$ primary $((1 / 3 \times(18-6))+6)$ porosity fit log derived values. For intervals with $0-6 \%$ porosity, little secondary (vuggy) porosity is present, and anhydrite is a major mineralogical component, causing the density tool to register abnormally low values. In intervals with only minor amounts of secondary porosity, the Sonic vs. NDXP cross-plot exhibits little deviation from a 1:1 relationship regardless of the total porosity. This data set matches the "Primary Porosity" data set from core data.

\section{Evaluation Of The Effectiveness Of Recent Completions Utilizing Water Analyses}

Analyses of produced water have become a standard method to determine if water production is from the San Andres or the lower Grayburg in the study area. Enough isolated water samples have been recovered to distinguish waters by their Sodium $(\mathrm{Na}+)$, Chloride (Cl-), and Total Dissolved Solids (TDS). Waters with TDS's of 60,000 64,000 PPM are San Andres in origin and waters with TDS's from 36,000 - 42,000 PPM are lower Grayburg in origin (Fig. 23). 
The Witcher-12 (WH-12) produced water sampled two weeks after the lower Grayburg completion, indicated the water is almost entirely from the San Andres $(60,000$ PPM TDS). As the fracture completion was designed to frac the lower Grayburg and frac down into the San Andres, this was expected.

The Foster-11 (FS-11) produced water was sampled a number of times after completion in the lower Grayburg and the analyses indicate a steady increase in the San Andres component in the water. This was not anticipated, as the perforations and fracture treatment were designed to stay in the lower Grayburg only.

During the first quarter of 1997, the Witcher-2 (WH-2), was plugged back from the San Andres and recompleted in the lower Grayburg. A different type of fracture treatment, a "Pipeline Frac" (see ENGINEERING), was utilized in an attempt to stay "in zone" in the lower Grayburg and not fracture down into the San Andres (see first quarter 1997 report for details). At the end the first quarter 1997, the WH-2 well had just begun pumping and had not stabilized. During the second quarter 1997, the well IP'd pumping at a rate of $110 \mathrm{BO}, 210 \mathrm{BW}, 12 \mathrm{MCFGPD}$, dropping to $66 \mathrm{BO}, 140 \mathrm{BW}, 16 \mathrm{MCFGPD}$ at the end of the quarter. In contrast the WH-12 had IP'd pumping 60 BO, $400 \mathrm{BW}, 10$ MCFGPD, falling to $25 \mathrm{BO}, 180 \mathrm{BW}, 8$ MCFGPD over a similar time period. Produced water analyses indicated that the "Pipeline Frac" had indeed stayed in zone as the produced water from the WH-2 contained 37,000 PPM total dissolved solids (TDS), indicative of uncontaminated lower Grayburg water. The produced water samples collected from the WH-2 San Andres interval consistently tested at 62,000 PPM TDS.

In contrast, the produced water from the $\mathrm{WH}-12$, completed with a conventional frac, initially contained 48,000 PPM TDS, rising to 64,000 PPM TDS after 3 months. This indicated that the initial production was a mix of lower Grayburg and San Andres, increasing to $100 \%$ San Andres water within three months.

Evaluation of the effectiveness of recent completions, plug backs and injector conversions by monitoring produced water composition continues. The Foster-Pegues- 4 (FP-4), was converted to injection during the first quarter 1997. The Foster-Pegues-5 (FP-5), the offset well to the west, experienced an increase in production beginning in April. At the end of the 2nd quarter 1997, however, the FP-5 had experienced flood water break through and injection into the FP-4 well had been reduced. Both the FP-4 and FP-5 are being closely monitored.

From discussions with Robert Lindsay, Senior Petrographer of Chevron, this type of break through response is not unusual in Grayburg shallow shelf carbonates. Thin (from 1 - $6 \mathrm{ft}$ thick), transgressive grainstones at the base of thick (30 - 50 ft) sequences can exhibit normal porosity $(6-12 \%)$, but very high permeabilities (R. Lindsay reports values as high as 1 Darcy in these intervals at Eunice Monument South Unit). The interval suspected of causing the break through in the FP-5 is correlated with an ooid grainstone in the core in the Witcher-6 1/2 mile to the north.

Water sampling and analyses on both producing and injection wells will continue. All 
producing wells and injection water stations were sampled in May 1996. All the wells and injection stations will be resampled yearly to provide a base line.

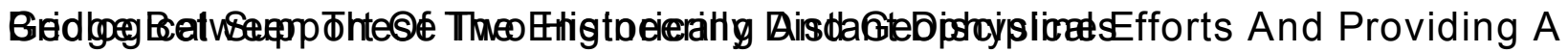

Historically, field studies and simulations in mature fields have been conducted by the engineer and geologist, while the geophysicist and the geologist look at the same property hoping to develop new pool, stratigraphic, or down dip reserves utilizing 2D and 3D. This project attempts to integrate all three disciplines in the evaluation of a mature field, and at a scale reflective of an independent operator's holdings. One of the main problems has been integrating engineering and geophysical understanding of a field. Although both disciplines work at similar scales, (110 by $110 \mathrm{ft}$ bins in a seismic, and 100 by $100 \mathrm{ft}$ cells in a reservoir simulation, 5 - 10 millisecond seismic intervals and $40-120 \mathrm{ft}$ thick flow units), their understanding of the other disciplines abilities, limits, and data requirements are not always clear. Because both disciplines are used to working closely with the geologist, the gap between the geophysical and engineering sciences appears to be best bridged by the geologist. During Phase Two of this project, the geologist has also become the project manager. It is in the dual role of project manager and geologist that communication and understanding among the three disciplines has expanded. Although it is not recommended that the geologist manage every tri-discipline project, it has become evident that until the engineering and geophysical disciplines become more familiar with each others' areas, the geologist can best bridge this gap.

\section{ENGINEERING}

\section{Engineering Objectives}

Together with the continuous testing and monitoring of bottom hole pressures, individual well production, injection volumes, injection pressures, injection profiles and day to day operations, the engineering objectives of the year were to:

* Implement recommendations derived from the simulation that was based upon geologic and historical data.

- $\quad$ Drilling of the H. C. Foster-11

- $\quad$ Deepening of the Witcher-2

- $\quad$ Drilling of the Witcher-12

- $\quad$ Conversion of the Foster-Pegues-4 into a water injection well.

* Initiate and complete a simulation using seismically derived porosity maps. 
* Improve fracture treatment techniques in order to achieve greater frac lengths and reduce frac height growth.

* Improve the quality of the water injection and develop a chemistry database of produced and injected waters.

\section{H.C. Foster-11 (FS-11)}

During the third quarter of 1996, the H. C. Foster-11 (FS-11) was drilled to test the simulation results that indicated additional reserves could be contacted in the San Andres and the lower Grayburg formations. The well was located in the southwest quarter of section 36 to take advantage of the lack of producing wells in the West half of the southwest quarter of the section (Fig. 1a). The well is $690 \mathrm{ft}$ northwest of the $\mathrm{H}$. C. Foster-4 (FS-4), and $690 \mathrm{ft}$ southwest of the H. C. Foster-3 (FS-3), two 40-acre wells drilled in 1941. The FS-4 was plugged in 1984 and the FS-3 in 1986. The FS-3 was successfully reentered in 1996 (see First Quarter 1996 report) and placed back on production in the $\mathrm{A} 1$ zone.

The FS-11 was drilled to $4403 \mathrm{ft}$. A full suite of logs: Compensated Neutron, Three Detector Density, Long Spacing Sonic, Dual Laterolog, Micro-CFL, Spectral Gamma Log and Mud Log were run (Fig. 16). Additionally, a Repeat Formation Tester was employed in an effort to obtain reservoir pressure data. Eighteen tests were attempted in the San Andres, lower and upper Grayburg. However, only six good tests, and two formation fluid samples were recovered (Table 1). The results indicated the San Andres and the lower Grayburg are in different pressure regimes, and the A1 Zone is pressure depleted. A Core was cut in the lower Grayburg and San Andres to provide rock property information for these two intervals (See GEOLOGY). Casing was set through the San Andres to $4369 \mathrm{ft}$.

Table 1. Production test and pressure test data.

\section{PRODUCTION TEST DATA}

\begin{tabular}{lllrr} 
WELL & DATE & $\begin{array}{c}\text { DAYS ON } \\
\text { TEST }\end{array}$ & \multicolumn{1}{c}{ OIL RATE } & W/D \\
& & & & WATER RATE \\
BR-2 & $12 / 12 / 95$ & 3 & 3.39 & 25.30 \\
BR-5 & $12 / 25 / 95$ & 3 & 11.24 & 10.39 \\
BR-6 & $1 / 03 / 96$ & 3 & 6.00 & 6.00 \\
BR-7 & $12 / 11 / 95$ & 5 & 9.64 & 4.80 \\
BR-8 & $1 / 4 / 96$ & 3 & 4.10 & 10.20 \\
BR-9 & $1 / 8 / 96$ & 6 & & -207.00 \\
BR-10 & $1 / 2 / 96$ & 4 & 3.00 & 56.00 \\
BR-13 & $12 / 18 / 95$ & 3 & 32.00 & 15.00 \\
FP-3X & $1 / 18 / 96$ & & & -150.00 \\
FS-1 & $1 / 3 / 96$ & 4 & & -231.00 \\
FS-2 & $1 / 9 / 96$ & 6 & 5.30 & 16.80 \\
FS-5 & $1 / 10 / 96$ & 4 & & -107.00 \\
FS-6 & $1 / 3 / 96$ & 4 & & -230.00 \\
FS-7 & $1 / 10 / 96$ & 3 & 1.40 & 3.00 \\
FS-8 & $1 / 15 / 96$ & 3 & 5.00 & 40.00 \\
JN-6 & $1 / 15 / 95$ & 4 & &
\end{tabular}

PRESSURE TEST DATA

$\begin{array}{ccrrr}\begin{array}{c}\text { PRESS } \\ \text { AVE. }\end{array} & \text { PERM } & \begin{array}{c}\text { FRAC } 1 / 2 \\ \text { LNG }\end{array} & \begin{array}{c}\text { SKIN } \\ \text { DMG }\end{array} & \begin{array}{c}\text { RADIUS OF } \\ \text { INV }\end{array} \\ 539.60 & 0.3996 & 5.20 & 0.42 & 286 \\ 380.30 & 0.4802 & 40.30 & 0.31 & 150 \\ 420.80 & 0.2750 & 50.00 & 1.08 & 116 \\ 546.70 & 1.163 & 4.10 & 0.18 & 273 \\ 340.20 & 0.1857 & 103.50 & 0.73 & 126 \\ 2178.80 & 64.18 & 4.70 & 3.03 & 2763 \\ 535.00 & 0.1411 & 3.5 & 0.80 & 259 \\ 567.80 & 2.477 & 4.10 & 0.80 & 300 \\ 2255.40 & 7.0 & 1.00 & 0.07 & 1391 \\ 2212.50 & 16.53 & 95.70 & 1.72 & 1401 \\ 1477.01 & 0.816 & 4.50 & 1.86 & 288 \\ - & 3.096 & 16.50 & 2.56 & \\ 2009.20 & 8.06 & 479.90 & 0.51 & 971 \\ 187.60 & 0.1357 & 1.90 & 7.05 & 141 \\ 3132.80 & 0.01648 & 49.00 & 0.00 & 61 \\ 769.50 & 28.03 & 1.00 & 10.60 & 969\end{array}$


The FS-11 was initially completed in the San Andres formation based on log calculations and core recoveries. The interval from $4238(-1311)-4323 \mathrm{ft}(-1396)$ was perforated and acidized with 1500 gallons $15 \% \mathrm{NeFe}$ acid. Following the acid treatment production rates of 3 - 4 BOPD and 6 - 8 BWPD were established. The well had to be fracture treated to increase production, but because water bearing zones were indicated both above and below the perforated interval, a fracture treatment had to be designed to minimize frac height growth in an attempt to stay out of these zones. A "Mini Frac" consisted of a first stage of pumping 3500 gallons of cross-linked gel and 6000 pounds of 100 mesh sand into the perforations. This stage was immediately followed with 2000 gallons of nitrified cross-linked gel and 6000 pounds of sand. The small stimulation failed to achieve economic levels of production as the well was producing at rates of 3 BOPD, 15 BWPD and 2 MCFPD after being on production for less than three months. A bottom hole pressure test indicated the frac wing length to be less than $30 \mathrm{ft}$, which confirmed the belief that the fracture treatment was too small to be successful. Therefore, a larger fracture treatment would be necessary on the San Andres to achieve economic production.

However a larger stimulation was not attempted because it was felt the frac height growth could not be controlled enough to stay out of water bearing zones above and below the perforated interval. Thus the well was plugged back and perforated in the lower Grayburg from $4030(-1103)$ - $4035 \mathrm{ft}(-1108)$. The lower Grayburg was perforated in this manner in order to coincide with a frac design of treating the interval from midpoint and allowing the fracture treatment to grow vertically throughout the gross producing interval. Again, in an attempt to limit frac height growth, a small fracture treatment was designed for the interval. It was attempted to frac the zone utilizing a small pre-frac pad of crossed-linked gel followed by a sand laden cross-linked gel. However, the small pre-frac pad caused the treatment to prematurely screen out resulting in very little propant being pumped into the formation. Again low producing rates were achieved.

To obtain a commercially productive well it was decided a much larger fracture treatment had to be utilized although a larger treatment would produce frac heights of much greater lengths than desired. In January of 1997, an additional $10 \mathrm{ft}$ of interval was perforated increasing the interval to $4020(-1093)-4035 \mathrm{ft}(-1108)$. The interval was fracture treated with 30,000 gallons of $50 \mathrm{lbs}$ linear gel and $85,420 \mathrm{lbs}$ of $20 / 40$ Ottawa sand. After achieving producing rates of up to 35 BOPD, the well potentialed for $27 \mathrm{BO}, 240 \mathrm{BW}$ and $20 \mathrm{MCF}$. A build up test on the lower Grayburg indicated near virgin reservoir pressure (2037 psi) as predicted by the simulation.

Witcher-2 (WH-2)

During the third quarter of 1996, the first deepening of an existing well was completed. The Witcher-2 (Fig.1) is one of the original 40-acre wells drilled in the 1940's. It was originally completed open hole and shot with nitro in the upper Grayburg with TD being $20 \mathrm{ft}$ above the top of lower Grayburg. The well was deepened through the San Andres down to $4450 \mathrm{ft}$. No cores were taken during the deepening of this well but a full suite 
of logs: Compensated Neutron, Three Detector Density, Long Spacing Sonic, Dual Laterolog, Micro-CFL, and Spectral Gamma Log and Mud Log were run. Located in the northwest quarter of section 36, the purpose of the well was to test the lower Grayburg and determine if the San Andres was below the "historic" oil/water contact. Simulation results indicated untapped reserves in the lower Grayburg at this location and the "historic" oil/water contact of -1340 in the San Andres is coincident with the top of San Andres (-1334) at this location. There has been production in other wells deeper than -1340 and this location was chosen to test the paradigm.

The well was initially perforated in the San Andres from $4389(-1462)-4398 \mathrm{ft}(-1471)$ and acidized with 1000 gallons $15 \% \mathrm{NeFe}$ acid. The well flowed $100 \%$ water at rates of 240 BWPD. A CIBP was set at $4360 \mathrm{ft}$ and the well was re-perforated at $4291 \mathrm{ft}$ $(-1364), 4301 \mathrm{ft}(-1374)$ and $4325 \mathrm{ft}(-1398)$. The intervals were acidized with 1500 gallons $15 \% \mathrm{NeFe}$ and tested at rates of $200 \mathrm{BFPD}$ with a high water cut. Production logs indicated the interval of $4325 \mathrm{ft}(-1398)$ was producing $100 \%$ water, thus a CIBP was set at $4318 \mathrm{ft}$. The well was put on pump and produced at rates of 60 BOPD, 120 BWPD and 10 MCFPD from perforations at $4291 \mathrm{ft}$ and $4301 \mathrm{ft}$. The production declined to 5 BOPD, 60 BWPD and 2 MCFPD in three months. This is believed to be a result of the low permeability associated with the San Andres (see GEOLOGY). This proves however, that the "historic" oil/water contact needs revision. Based on core and log evaluations, It is now believed that the San Andres has multiple oil/water contacts. This will be tested in future new drills and deepenings.

In March of 1997 the well was plugged back due to low producing rates. A CIBP was set at $4280 \mathrm{ft}$ and the lower Grayburg was perforated from $4190(-1263)-4240 \mathrm{ft}$ $(-1313)$. The zone was acidized with 2500 gallons $15 \% \mathrm{NeFe}$ acid. As in the past there was a need to fracture treat an interval yet limit the frac height growth to the productive zone. A relatively new frac technique called "Pipeline Frac" was employed. A "Pipeline Frac" consist of pumping a very large cross-linked gel pad followed by a small volume of sand laden Linear gel. The theory behind the "Pipeline Frac", is that the technique utilizes the differential viscosity's of two fluids to cause viscous fingering while pumping the fluids. This allows the selective placement of propant across the perforated interval when no stress barriers are present above and below the producing horizon.

The lower Grayburg was "Pipeline" fraced with 36,000 gallons of $35 \mathrm{lb}$ cross-linked gel, 17,500 gallons of linear gel and $53,640 \mathrm{lbs}$ of $16 / 30$ Ottawa sand. The well was put on pump and three days after recovering the frac load was producing 106 BOPD, 216 BWPD and 11 MCFPD. The well potentialed for 87 BOPD, 168 BWPD and 12 MCFPD.

The initial bottom hole pressure buildup test for the lower Grayburg in this new completion was conducted 45 days after the workover. When this test was conducted, the well was producing 85 BOPD, 170 BWPD and 11 MCFPD. Foam in the annulus dominated early time data, making the analysis uncertain. However, qualitative analysis indicates a skin of about -5 and a $200 \mathrm{ft}$ frac wing length. This frac wing length is far greater than the $30-50 \mathrm{ft}$ frac wing length achieved in wells utilizing more conventional fracture techniques. It is apparent the "Pipeline" fracture treatment demonstrated to be 
successful at creating greater depths of penetration of the sand laden fluid into the formation without producing large fracture height growth. The produced water chemistry (see GEOLOGY) also supports the fact that the fracture treatment stayed within the lower Grayburg.

Through the first six months of production, the well has produced 11,850 BO and 1,777 MCF from the lower Grayburg. The well is currently producing $47 \mathrm{BO}, 102 \mathrm{BW}$ and 10 MCF per day.

Witcher-12 (WH-12)

During the fourth quarter 1996, the Witcher-12 (WH-12) was drilled to test the simulation and contact additional reserves in the San Andres and the lower Grayburg. It located in the southwest corner of the northeast quarter of section 36 to take advantage of the lack of producing there. The well is $330 \mathrm{ft}$ southwest of the Witcher-4 WIW (WH-4), a well drilled on 40 acre spacing in 1941, converted to injection in 1961, and plugged in 1991. It is $690 \mathrm{ft}$ north of the Foster-Pegues-8.

The well was drilled to $4435 \mathrm{ft}$. A full suite of logs: Compensated Neutron, Three Detector Density, Long Spacing Sonic, Dual Laterolog, Micro-CFL, Spectral Gamma Log and Mud Log were run (Fig. 16). Additionally, a Repeat Formation Tester was employed in an effort to obtain reservoir pressure data. Twelve unsuccessful tests were attempted, with two different pad configurations before the effort was abandoned. A Core was cut in the lower Grayburg and San Andres to provide rock property information for these two intervals. Production casing was set through the San Andres to $4432 \mathrm{ft}$. Initially the two uppermost of three porosity zones in the San Andres were tested (see GEOLOGY). The middle zone was tested first; perforated from $4318(-1379)$ - $4330 \mathrm{ft}(-1391)$ and acidized with 1200 gals $15 \%$ NEFE acid. The zone swabbed dry in two hours, with entry rates thereafter of $400 \mathrm{ft}$ of fluid per hour with $15 \%$ oil cut. A CIBP was set at $4310 \mathrm{ft}$ and the uppermost zone was perforated from $4275(-1336)-4287 \quad$ (1348) ft, and acidized with 1850 gals 15\% NEFE acid. This zone swabbed dry in $11 / 4$ hours, and had entry rates of $500 \mathrm{ft}$ of fluid per hour with a $10 \%$ oil cut thereafter. These entry rates would not have resulted in a commercially successful well without additional stimulation. Because of the potential for water encroachment from the zone below 4375 $\mathrm{ft}$, it was decided not to fracture stimulate the San Andres zones.

Because of previous failures to successfully fracture stimulate the San Andres without producing large volumes of water, a different methodology had to be applied. It was decided to fracture stimulate a porous interval in the lower Grayburg, with the anticipation that the frac height of a "conventional" frac would be sufficient to grow down to the productive intervals in the San Andres but not enough to communicate with the water bearing interval below $4375(-1336) \mathrm{ft}$. The lower Grayburg was perforated from $4166(-1227)-4182 \mathrm{ft}(-1243)$ and acidized with 1250 gallons of $15 \%$ NEFE acid. The interval was then fracture treated with 23,520 gallons of 35 lbs cross-linked gel and 125,500 lbs $16 / 30$ Brady sand. 
The well potentialed pumping 55 BOPD, 372 BWPD and 16 MCFPD. The water analyses (see GEOLOGY) indicates the majority of the produced water is from the San Andres formation that indicates that the attempt to frac down into the San Andres was accomplished. At the end of the second quarter 1997, production was $28 \mathrm{BO}, 180 \mathrm{BW}$, and 10 MCFGPD.

Foster-Pegues-4 (FP-4)

The Foster-Pegues-4 (FP-4) was converted into a water injection well in the first quarter of 1997. This well, originally directionally drilled under the interstate, had been shut in for lack of production since 1992. Simulation results indicated this location would provide lower Grayburg pressure support for the recently completed Foster-Pegues-11 and upper Grayburg support for the Foster-Pegues-10 (FP-10), a plug back completed in November 1995.

The FP-4 was cleaned out to $4370(-1433), 7 \mathrm{ft}$ below existing perforations. The well was originally perforated in the upper Grayburg from 3919 (-982) - $4028 \mathrm{ft}(-1091)$ and in the lower Grayburg from $4130(-1193)-4307 \mathrm{ft}(-1370)$. Water Injection began in December of 1996. After stabilizing, the injection rate averaged 125 BWPD at 723 psig surface pressure. This is the first well to go on injection with the benefit of clean injection water (see produced water below).

It was hoped to inject water into the upper and lower Grayburg. However, an injection profile showed $100 \%$ to the water was entering the upper Grayburg with none entering the lower Grayburg. Both the injection rate and the injectivity profile were disappointing. A pressure fall off test was run to further diagnose the injectivity but was inconclusive due to an anomalously high storage coefficient. This high coefficient indicates a mechanical problem that will be evaluated. Produced water analyses were made of the FP-10 and Foster-Pegues-11 (FP-11), and of the injection water from FP-4, to create a base line for flood waters in this area. In addition, fluid levels and production tests in the producing wells, and injection pressures and injection rates will be monitored in the injection well.

\section{Simulation}

The first steps in the quantitative integration of seismic data into the reservoir simulation were taken this year. The A1 and A2 zone porosity maps, generated in the Vest seismic software package were imported as an array of $X, Y, Z$ points into the SSI WorkBench simulator during the second quarter 1997. The process is to work from top down, validating the seismic porosity maps with the history match process. The upper Grayburg has produced $81 \%$ of the oil and took $71 \%$ of the cumulative water injection. When the simulation of the upper Grayburg is completed using the seismically derived porosity maps, most of the waterflood history match will be done. Initial modeling analyses of $A$ and $B$ zone porosity maps are encouraging.

The objective of the waterflood history match is to optimize the sweep of the old flood by 
recompleting existing wells and drilling new wells. This is an iterative process which integrates geophysics, log analysis and reservoir simulation and it is not expected that the current maps will be the final ones. Seismic inversion modeling exhibited a high degree of correlation to the well data and a correlation was developed between seismic velocities and porosity for each zone (See GEOPHYSICS). An update of the production data spreadsheet is in progress so that the results of the recent well work can be incorporated in the match.

Production data for the model was updated through June 1997, using a spreadsheet system. The 1996 well work has affected sweep and this knowledge will be used to plan future well locations, injector conversions, and recompletions.

\section{Completions and Production}

Analysis of buildup and falloff tests continued on a routine basis. The results of these tests have been incorporated into the design of the fracture treatments. The main problem has been how to fracture the low permeability oil zones without communicating with the high permeability and high-pressure water zones. Well testing continues, reinforcing the preliminary conclusion that the water flood, as designed and implemented, is ineffective. One positive outcome of the well work has been the arrest of the decline for section 36 seen in the years prior to the implementation of study recommendations. Since June of 1993, the production has risen to 14,000 BOPM from 8700 BOPM (Fig. 24).

\section{Produced Water Suspended Solids Survey}

The Produced Water Suspended Solids Survey, found that: (a) $89 \%$ of the suspended solids are between .45 and .5 microns, (b) an injectivity enhancement chemical decreased overall suspended solids at the injection pump by $62 \%$ primarily by removing hydrocarbons from the solids, (c) the Brock and the Henderson leases contributed higher suspended solids waters to the unit, (d) a 30\% increase in suspended solids occurs when incompatible Canyon age waters with 105,000 PPM Total Dissolved Solids waters are mixed with 37,000 - 62,000 PPM San Andres and Grayburg waters, (e) a $65 \%$ suspended solids decrease occurs between the Gunbarrel Inlet and Gunbarrel Outlet, and (f) a further $8 \%$ suspended solids decrease occurs between the Gunbarrel Outlet and the Injection Pump Suction. The water system, therefore, is removing the majority of dissolved solids and only the Brock and Henderson leases need to be tested to see what corrective measures need to be taken. No other changes to the waterflood system surface facilities are planned at this time.

Continued work on the quality of the injection water has resulted in dramatic improvements in water quality. The size of solids in the injection system water has been reduced from over 100 microns at the start of the project, to less than 5 microns. This will enable the waterflood realignment to proceed, as it was thought to be counterproductive to clean out injection wells before to water quality was improved. 


\section{Delays}

The ongoing "mini-boom", the result of higher oil and gas prices this year, has delayed even simple well work. Drilling rigs, fracture trucks, downhole tools, surface equipment and workover rigs are all more expensive, in short supply and or must be scheduled up to six weeks in advance. This has resulted in unavoidable delays in implementing many of the recommendations.

\section{TECH TRANSFER}

Project personnel presented a paper titled "The Use of Core and Core Analysis in an Integrated Study of the Grayburg/San Andres Reservoir, Foster Field, Ector County, Texas" at the West Texas Geological Society 1996 Fall Symposium Permian Basin Oil and Gas Fields: Keys to Success That Unlock Future Reserves, on October 31 and November 1. The abstract appears on p.39 of the Symposium publication.

A paper titled "Impact of Subaerial Exposure on the San Andres Formation Reservoir, Foster Field, Ector County, Texas" was presented at the Luncheon Meeting of the PBSSEPM on February 18,1997, in Midland, Texas.

A poster session titled "Results of an Integrated Study of a Portion of the Grayburg/San Andres Reservoir, Foster and South Cowden Fields, Ector County, TX" was presented as part of the DOE Reservoir Class Program Workshop, at the Fourth Annual Reservoir Characterization Technical Conference, sponsored by the DOE, BDM OK, and AAPG, March 2-4,1997.

Project personnel presented current project results to attendees of the Southwestern Petroleum Short Course, sponsored by Texas Tech University, in Lubbock, Texas, in April 1997. The paper was titled "Progress Report on An Integrated Study of the Foster (Grayburg/San Andres) Field, Ector County, Texas". The presentation reviewed of the use of seismic data to map porosity in the upper Grayburg. The theme of the discussion was that seismic data can be obtained economically from the earth surface in great quantity to image the subsurface and be directly applied to geology and engineering models to improve oil field development.

An abstract titled "How an Independent Operator Can Integrate Engineering, Geophysics, and Geology in a Reservoir Study: Grayburg/San Andres of Foster and South Cowden Fields, Ector County, Texas" was submitted for, and will be presented to, the fall 1997, WTGS Symposium, October 30-31.1997.

An abstract titled "Practical Mapping of Lithology and Rock Properties using Analyses of Seismic Inversion Models" was submitted for and will be presented to the fall, 1997, WTGS Symposium, Oct. 30-31.1997. 


\section{REFERENCES}

Editor not credited, Porosity and Lithology Determination from Sonic Log and CNL* Compensated Log, Schlumberger Log Interpretation Charts, page 35, figure CP-2C, 1989.

Galloway, W.E., Ewing, T.E., Garrett, C.M., Jr., Tyler, N., and Bebout, D.G., 1983, Atlas of Major Texas Oil Reservoirs: the University of Texas at Austin, Bureau of Economic Geology Special Publication, $139 \mathrm{p}$.

Schultz, P.S., S.Ronen, M.Hattori, and C. Corbett, Seismic-guided estimation of log properties (in three parts), The Leading Edge, 305-310 (May), 674-678 (June), and 770776 (July), 1994.

Ruppel, S.C., and Lucia, F.J., 1996, Diagenetic Control of Permeability Development in a Highly Cyclic, Shallow-Water Carbonate Reservoir: South Cowden Grayburg Field, Ector County, Texas, in Permian Basin Oil and Gas Fields: Keys to Success That Unlock Future Reserves, WTGS Symposium, Oct. 31-Nov. 1,1996, Publication 96-101, R.L.Martin, editor, p. 7-23.

Ward, R.F., Kendall, C.G., and Harris, P.M.,1986, Upper Permian (Guadalupian) Facies and Their Association with Hydrocarbons - Permian Basin, West Texas and New Mexico: American Association of Petroleum Geologists Bulletin, v.70, no. 3, p.239-262.

Watts, G.P., G.D. Hinterlong, A.R. Taylor, 3-D Seismic evaluation for Reservoir Description, West Welch Unit, Dawson County, Texas, Oxy/DOE Class II Project Technical Report, 60 pages (plus figures), date presented: September 27, 1995.

\section{ACKNOWLEDGMENTS}

We would like to acknowledge James J. Reeves and Hoxie W. Smith for conceiving and managing the DOE study and for being responsible for the geophysical study. We would like to acknowledge that, since April 1996, William C. Robinson has been responsible for the reprocessing and reinterpreting the seismic data and for the geophysical study. Also, since that date, Robert C. Trentham has been responsible for project management. 


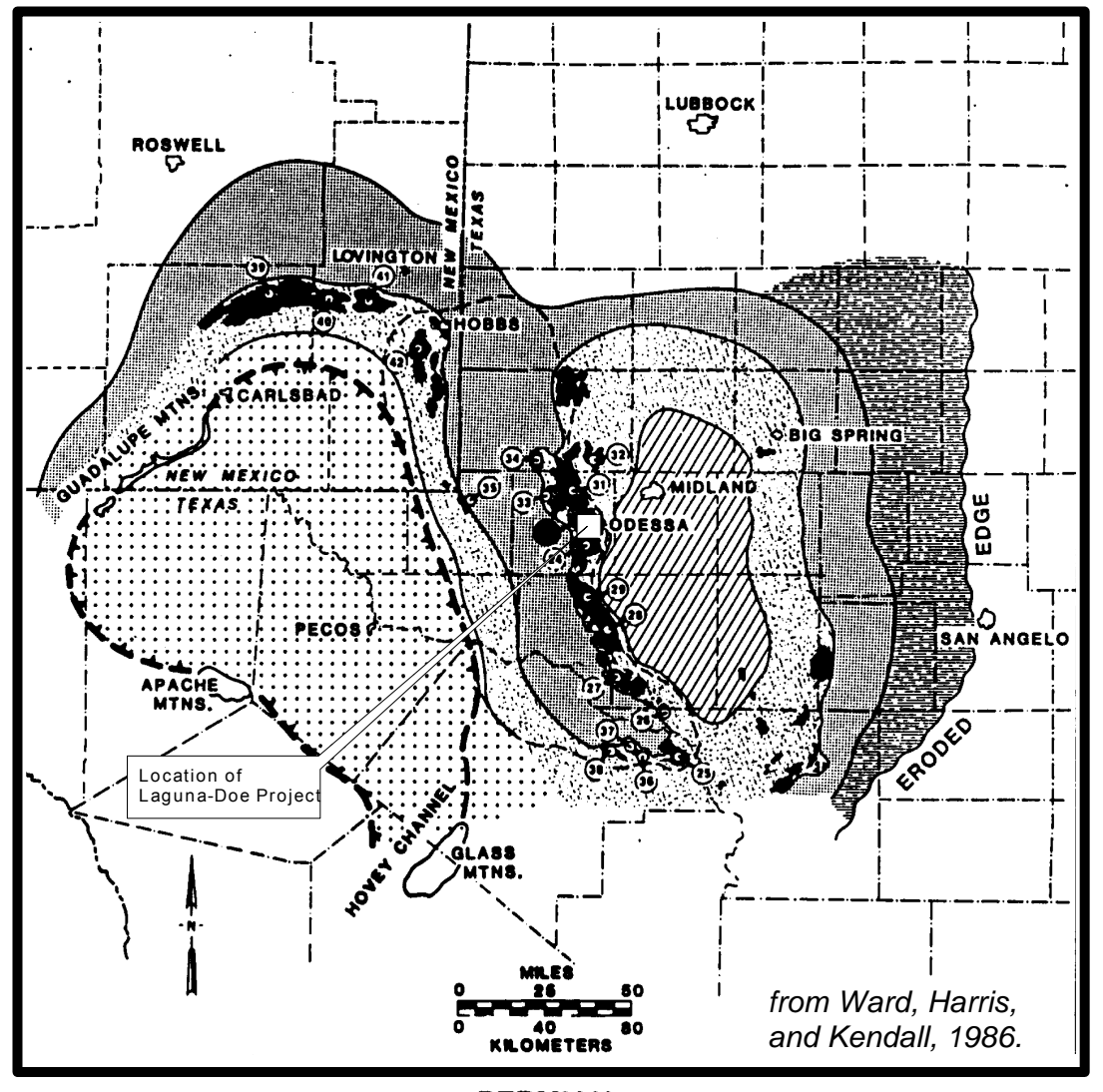

PERMIAN

MIDDLE GUADALUPE SERIES

GRAYBURG FORMATION

- T CAPITAN "REef" FRont (SUBSURFACE)

DELAWARE BASIN-CHERRY CANYON FORMATION BASINAL SANDSTONE, SILT, SHALE AND LIMESTONE

DOLOMITE

---- OUTLINE CENTRAL BASIN PLATFORM

(9) OILFIELDS LISTED IN TABLES

SIMPLIFIED GEOLOGIC MAP OF THE GRAYBURG FORMATION, PERMIAN BASIN, SHOWING THE LOCATIONS OF PRODUCING FIELDS. SEE TABLE 2 IN APPEN. DIX FOR DETAILED DESCRIPTIONS OF THE NUMBERED FIELDS.

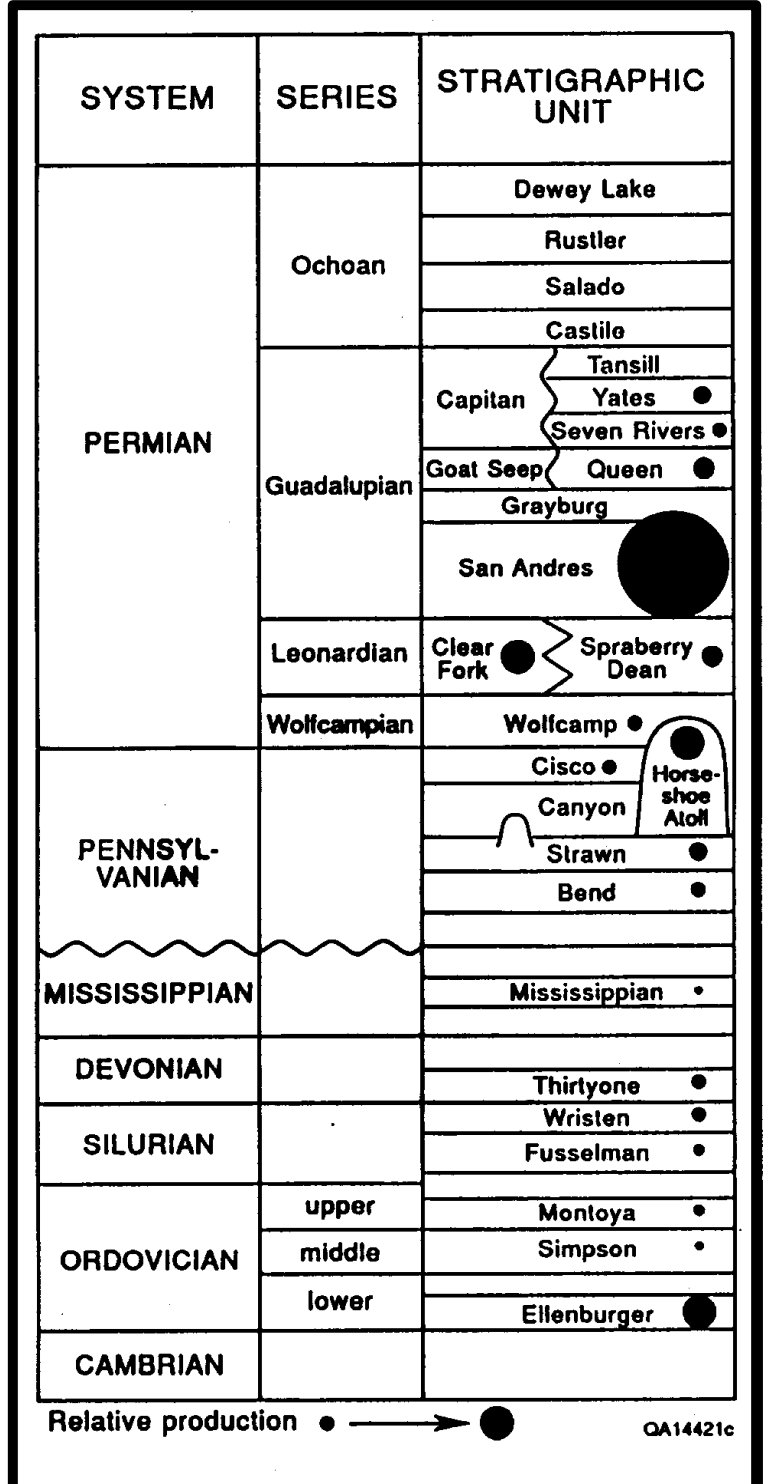

Paleozoic section in West Texas showing relative importance of oil producing unit (from Galloway and others, 1983).

Figure A. Location Map for the Laguna-DOE Project and Stratigraphic Column. 


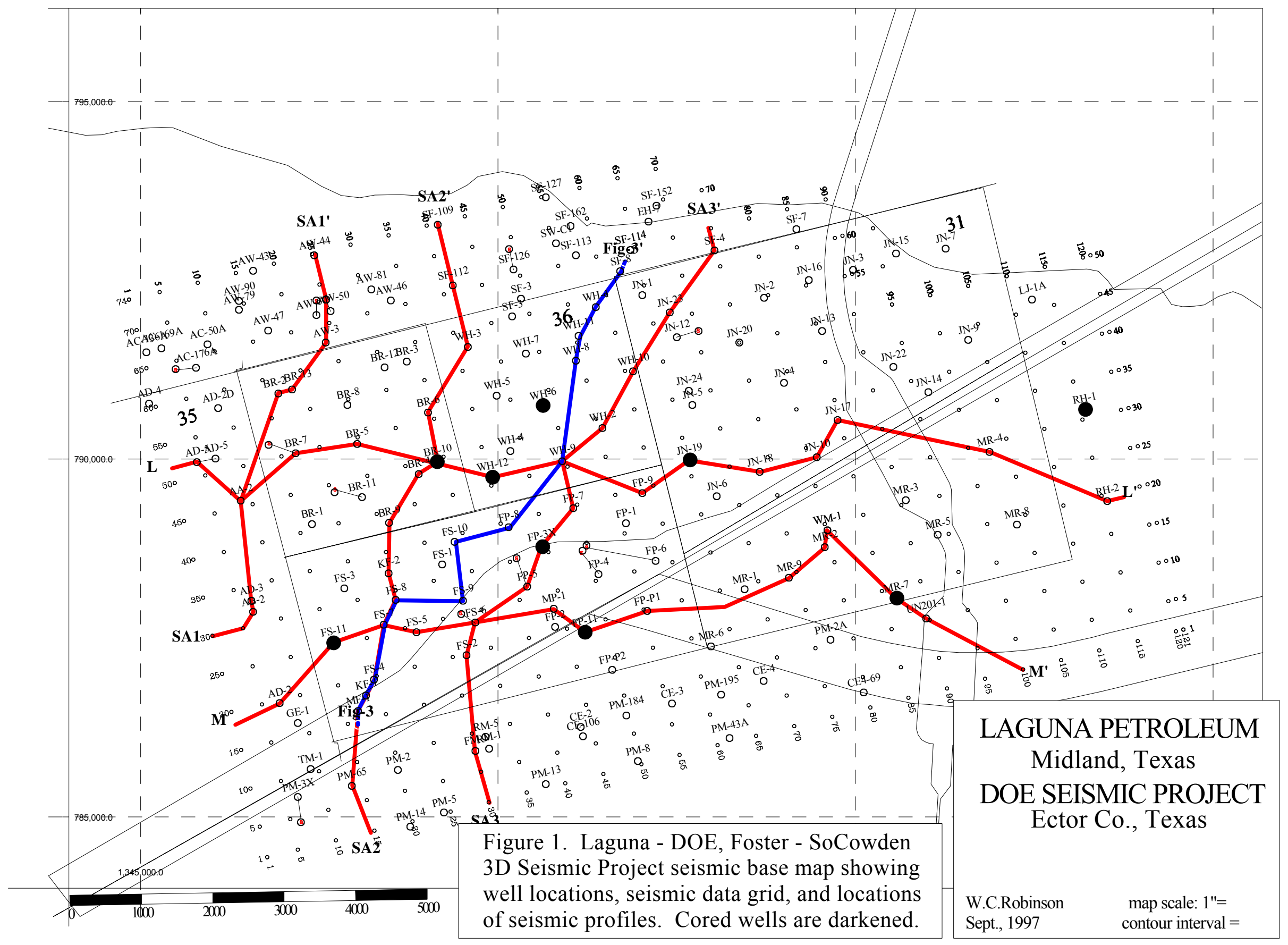




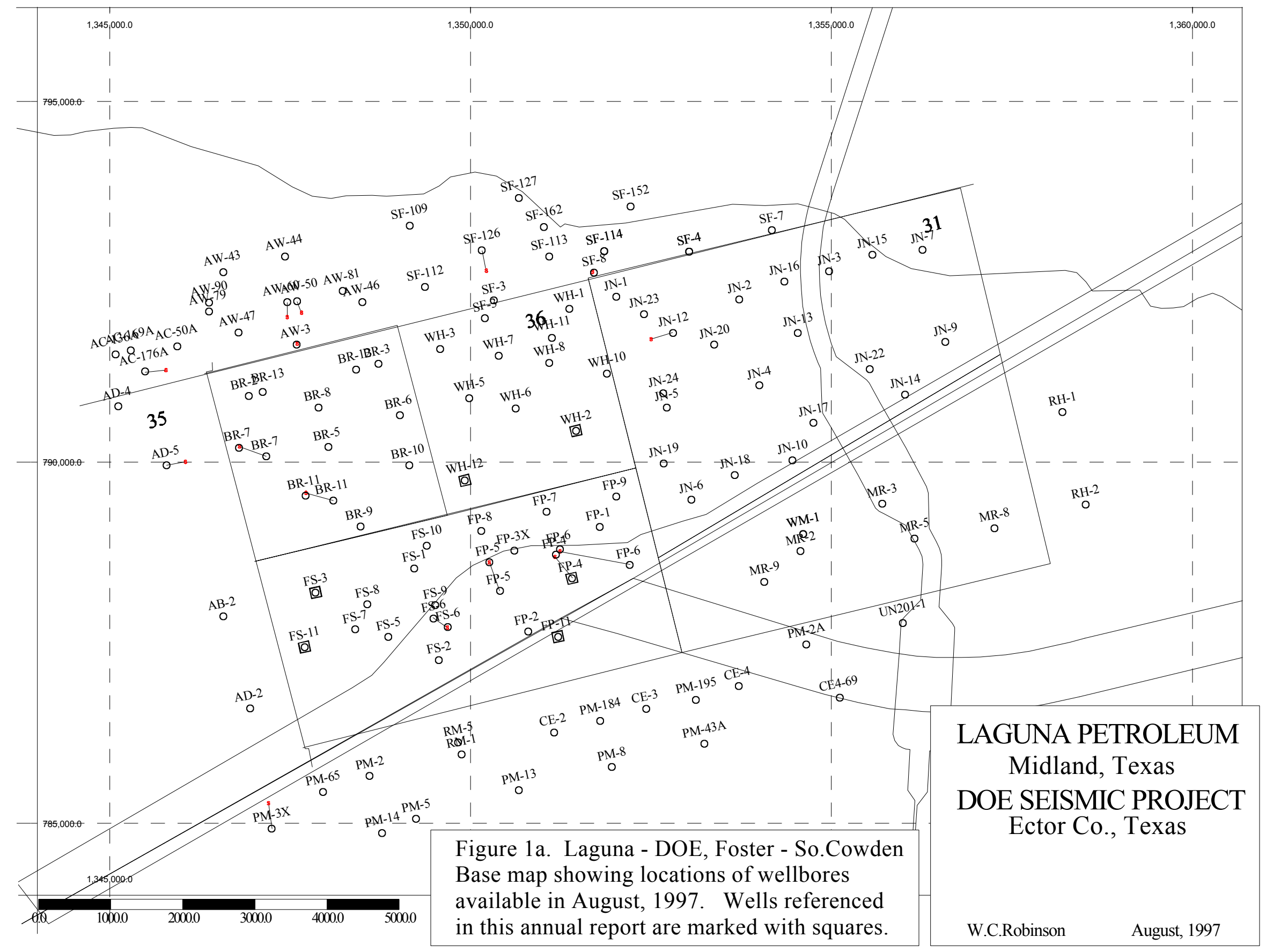


DOEWLL4

\begin{tabular}{|c|c|c|c|c|c|c|c|c|c|c|c|c|c|c|c|c|}
\hline X-DOE & Y & \#\# & elev & Oper & fee & wll\# & API \# & LogDatu & Yates & 7River & Queen & 1.Qn & Grbg & GrbgSS & GbA1 & GbA1A \\
\hline 1347123 & 790974 & BR-1: & 2927 & L.E. & BROCK & 13 & $4.214 \mathrm{E}+11$ & 2942 & 2694 & 2907 & 3236 & 3743.5 & 3816 & -874 & 3820.5 & 3848.5 \\
\hline 1347599 & 792231 & AW-50 & 2936 & AMOCO & WITCHER & 50 & $4.214 \mathrm{E}+11$ & 2937 & 2707 & 2920 & 3250 & 3764.5 & 3837 & -900 & 3837.5 & 3872.6 \\
\hline 1346402 & 789419 & AA-2 & 2938 & F.V. & ADDIS & A-2 & & & & & & & & & & \\
\hline 1346572 & 787863 & AB-2 & 0 & F.V. & ADDIS & B-2 & & & & & & & & & & \\
\hline 1345084 & 791492 & AC-136 & 2955 & AMOCO & COWDEN & $136-\mathrm{A}$ & $4.214 \mathrm{E}+11$ & 2955 & 2720.5 & 2932 & 3267.5 & 3794.5 & 3864 & -909 & 3865 & 3898.5 \\
\hline 1345293 & 791550 & AC-169 & 0 & AMOCO & COWDEN & $169-A$ & & & & & & & & & & \\
\hline 1345489 & 791258 & AC-176 & 0 & AMOCO & COWDEN & $176-A$ & & & & & & & & & & \\
\hline 1345939 & 791604 & AC-50A & 0 & AMOCO & COWDEN & $50-\mathrm{A}$ & & & & & & & & & & \\
\hline 1346945 & 786591 & AD-2 & 2940 & F.V. & ADDIS & 2 & $4.214 \mathrm{E}+11$ & 2954 & 2657.5 & 2871.5 & 3195.5 & 3696.5 & 3763 & -809 & 3765.5 & 3788.9 \\
\hline 1346084 & 790712 & AD-2D & 2941 & F.V. & ADDIS & 2 & & & & & & 3727 & 3794 & & 3796 & 3826 \\
\hline 1346550 & 788020 & AD-3 & 2936 & F.V. & ADDIS & 3 & $4.214 \mathrm{E}+11$ & 2948 & 2656 & 2866 & 3194 & 3691 & 3753 & -805 & 3753.5 & 3777.3 \\
\hline 1345118 & 790775 & AD-4 & 2931 & F.V. & ADDIS & 4 & $4.214 \mathrm{E}+11$ & 2953 & 2681 & 2892 & 3228.5 & 3755 & 3813.5 & -860.5 & 3818.5 & 3846.5 \\
\hline 1345790 & 789959 & AD-5 & 2943 & F.V. & ADDIS & 5 & & & & & & & & & & \\
\hline 1347593 & 791631 & AW-3 & 2925 & AMOCO & WITCHER & 3 & $4.214 \mathrm{E}+11$ & 2948 & 2698.5 & 2911.5 & 3241 & 3765 & 3828.5 & -880.5 & 3830 & 3865.7 \\
\hline 1346579 & 792634 & AW-43 & 2926 & AMOCO & WITCHER & 43 & & & & & & & & & & \\
\hline 1347433 & 792851 & AW-44 & 2927 & AMOCO & WITCHER & 44 & & & & & & & & & & \\
\hline 1348502 & 792216 & AW-46 & 2922 & AMOCO & \begin{tabular}{|l} 
WITCHER \\
\end{tabular} & 46 & & & & & & & & & & \\
\hline 1346788 & 791797 & AW-47 & 2928 & AMOCO & WITCHER & 47 & & & & & & & & & & \\
\hline 1347459 & 792217 & AW-60 & 2925 & $\mathrm{AMOCO}$ & WITCHER & 60 & $4.214 \mathrm{E}+11$ & 2934 & 2704.5 & 2919.5 & 3250.5 & 3771 & 3841 & -907 & 3842 & 3870 \\
\hline 1346376 & 792087 & AW-79 & 0 & AMOCO & WITCHER & 79 & & & & & & & & & & \\
\hline 1348232 & 792376 & AW-81 & 0 & AMOCO & WITCHER & 81 & & & & & & & & & & \\
\hline 1346375 & 792213 & AW-90 & 2943 & AMOCO & WITCHER & 90 & & & & & & & & & & \\
\hline 1347400 & 789095 & BR-1 & 2938 & L.E. & BROCK & 1 & & & & & & & & & & \\
\hline 1349153 & 789961 & BR-10 & 2924 & L.E. & BROCK & 10 & $4.214 \mathrm{E}+11$ & 2934 & 2677 & 2886 & 3217 & 3718 & 3797 & -863 & 3801.5 & 3827.5 \\
\hline 1348099 & 789473 & BR-11 & 2938 & L.E. & BROCK & 11 & & 2936 & 2647 & 2863 & 3201 & 3729 & 3803 & -867 & 3805.5 & 3834.5 \\
\hline 1347714 & 789535 & BR-11 & 2929 & surfaceLoc & & sfcloc & $4.214 \mathrm{E}+11$ & & & & & & & & & \\
\hline 1348413 & 791285 & BR-12 & 2923 & L.E. & BROCK & 12 & $4.214 \mathrm{E}+11$ & 2938 & 2694 & 2905 & 3236 & 3746 & 3819 & -881 & 3820.5 & 3850.5 \\
\hline 1346926 & 790922 & BR-2 & 2934 & L.E. & BROCK & 2 & & & & & & & & & & \\
\hline 1348722 & 791362 & BR-3 & 2920 & L.E. & BROCK & 3 & $4.214 \mathrm{E}+11$ & 2938 & & & & 3736 & 3818 & -880 & 3822 & 3846 \\
\hline 1348889 & 789795 & BR-4 & 2931 & L.E. & BROCK & 4 & & & & & & & & & & \\
\hline 1348029 & 790212 & BR-5 & 2927 & L.E. & BROCK & 5 & $4.214 \mathrm{E}+11$ & 2941 & & & & 3725.5 & 3800 & -859 & 3803 & 3833 \\
\hline 1349019 & 790653 & BR-6 & 2923 & L.E. & BROCK & 6 & $4.214 \mathrm{E}+11$ & 2933 & 2684 & 2900 & 3232.5 & 3740 & 3819.5 & -886.5 & 3821 & 3850.5 \\
\hline 1347171 & 790085 & BR-7 & 2939 & L.E. & BROCK & 7 & & 2939 & 2661 & 2880 & 3222 & 3739 & 3808 & -869 & 3810 & 3839.5 \\
\hline 1346791 & 790200 & BR-7 & 2929 & surfaceLoc & & sfcloc & $4.214 \mathrm{E}+11$ & & & & & & & & & \\
\hline 1347898 & 790758 & BR-8 & 2925 & L.E. & BROCK & 8 & $4.214 \mathrm{E}+11$ & 2935 & 2688 & 2900 & 3230 & 3741 & 3816 & -881 & 3819.5 & 3848 \\
\hline 1348478 & 789113 & BR-9 & 2927 & L.E. & BROCK & 9 & $4.214 \mathrm{E}+11$ & 2937 & 2657 & 2873 & 3205 & 3697.5 & 3770 & -833 & 3774.5 & 3796.5 \\
\hline
\end{tabular}

Figure 2. Example from the well data spreadsheet for the Foster - So. Cowden project. 


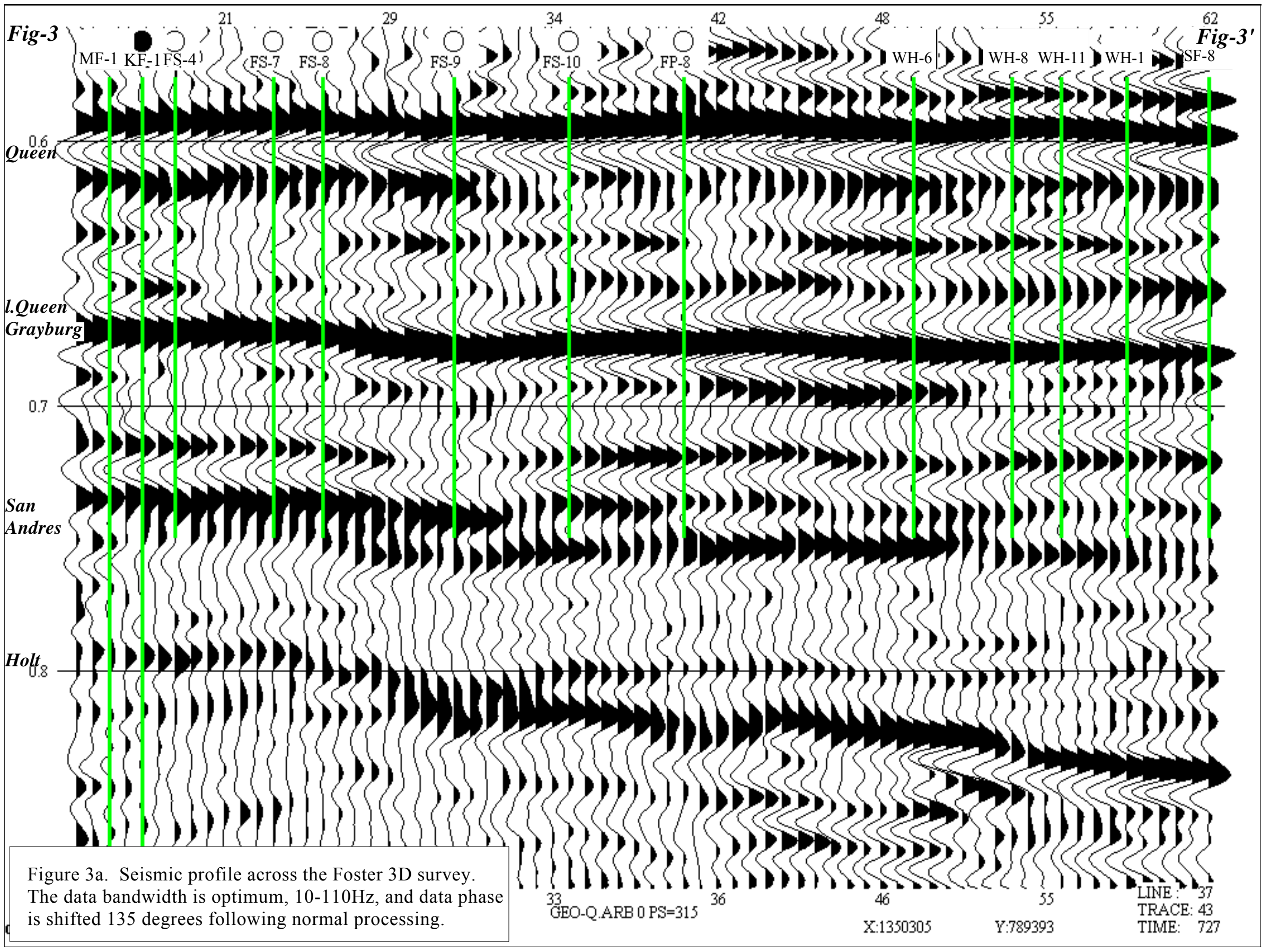




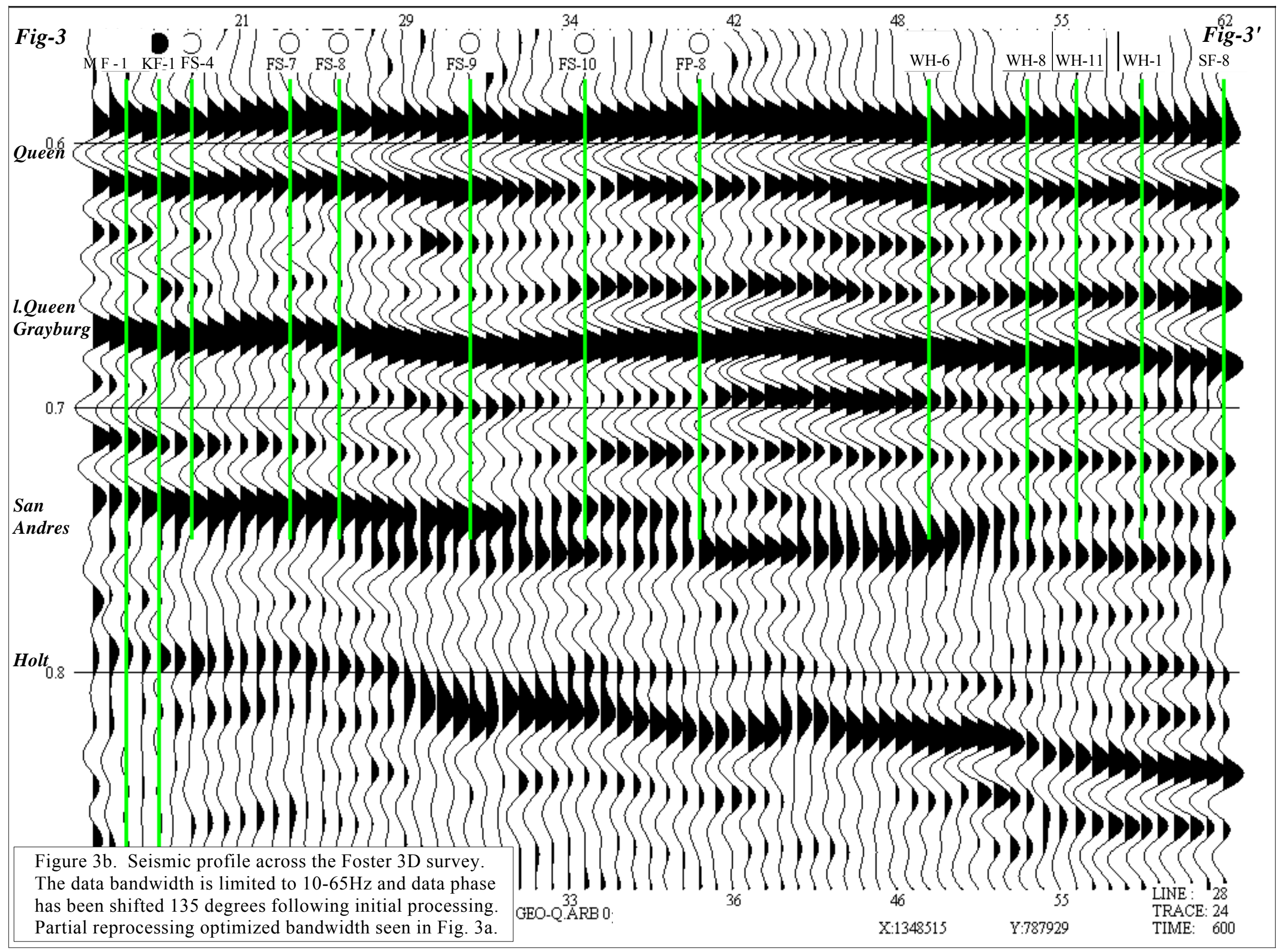




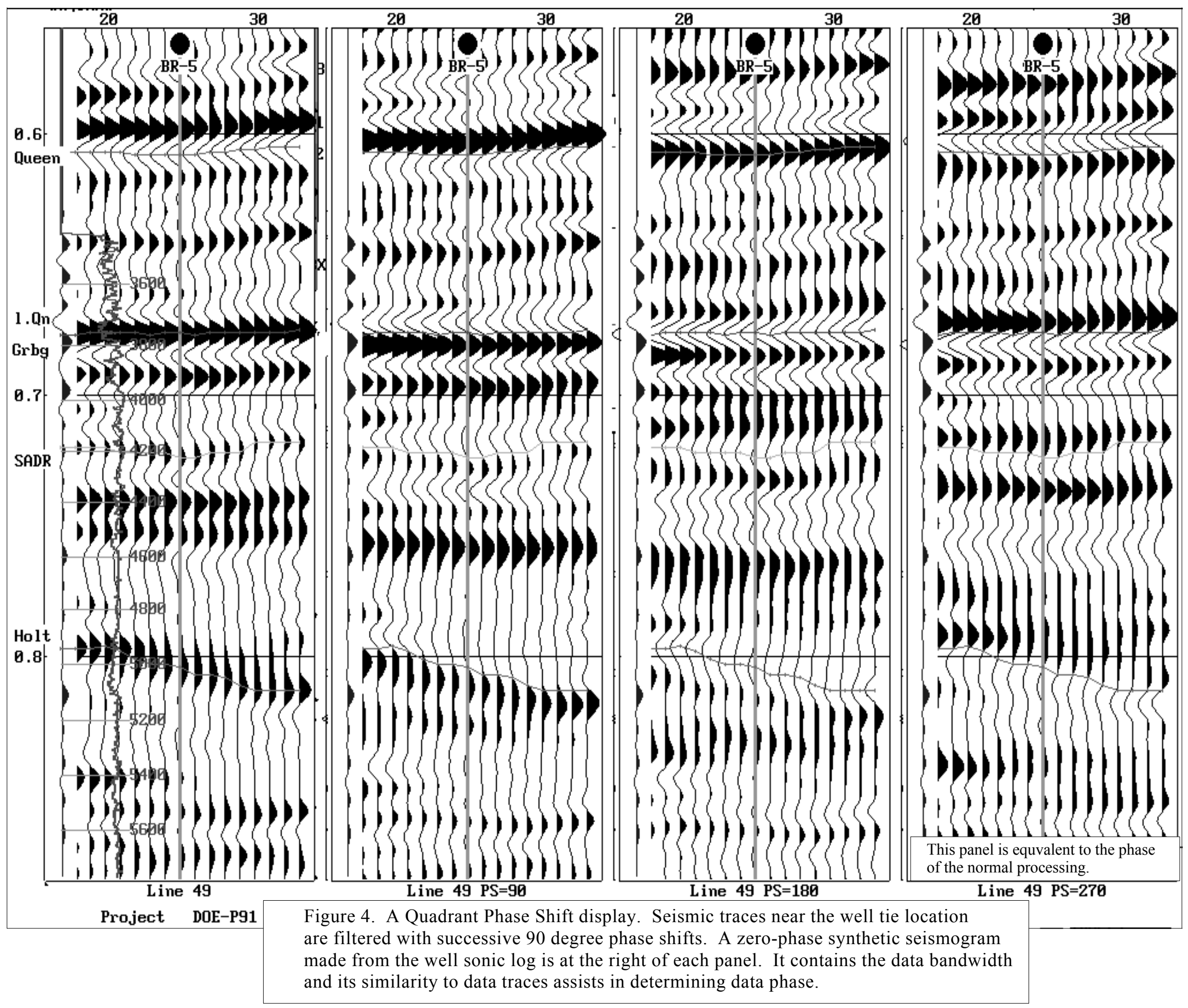




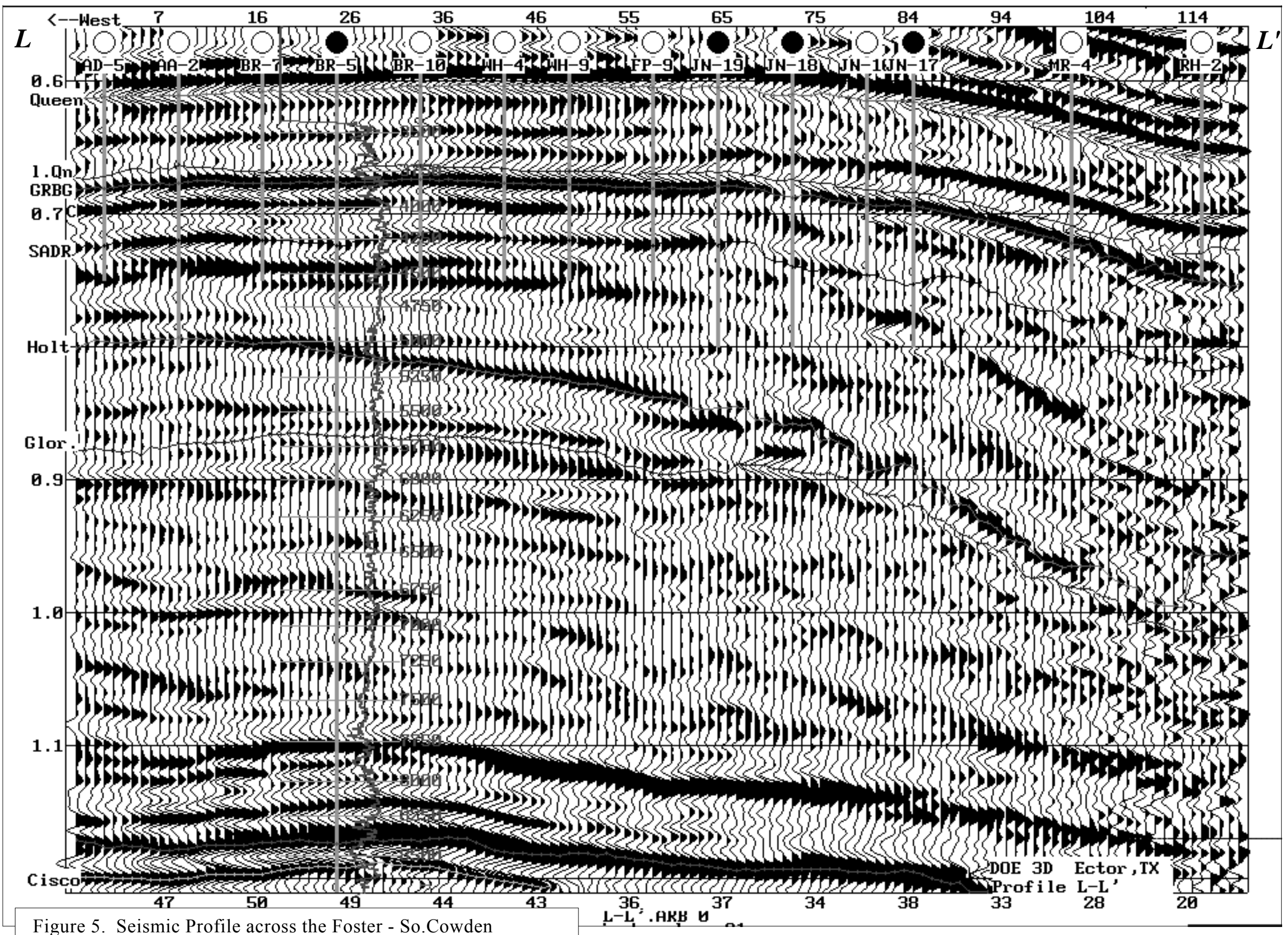

Figure 5. Seismic Profile across the Foster - So.Cowden

3D seismic survey, showing some structural and

stratigraphic features of the project. 


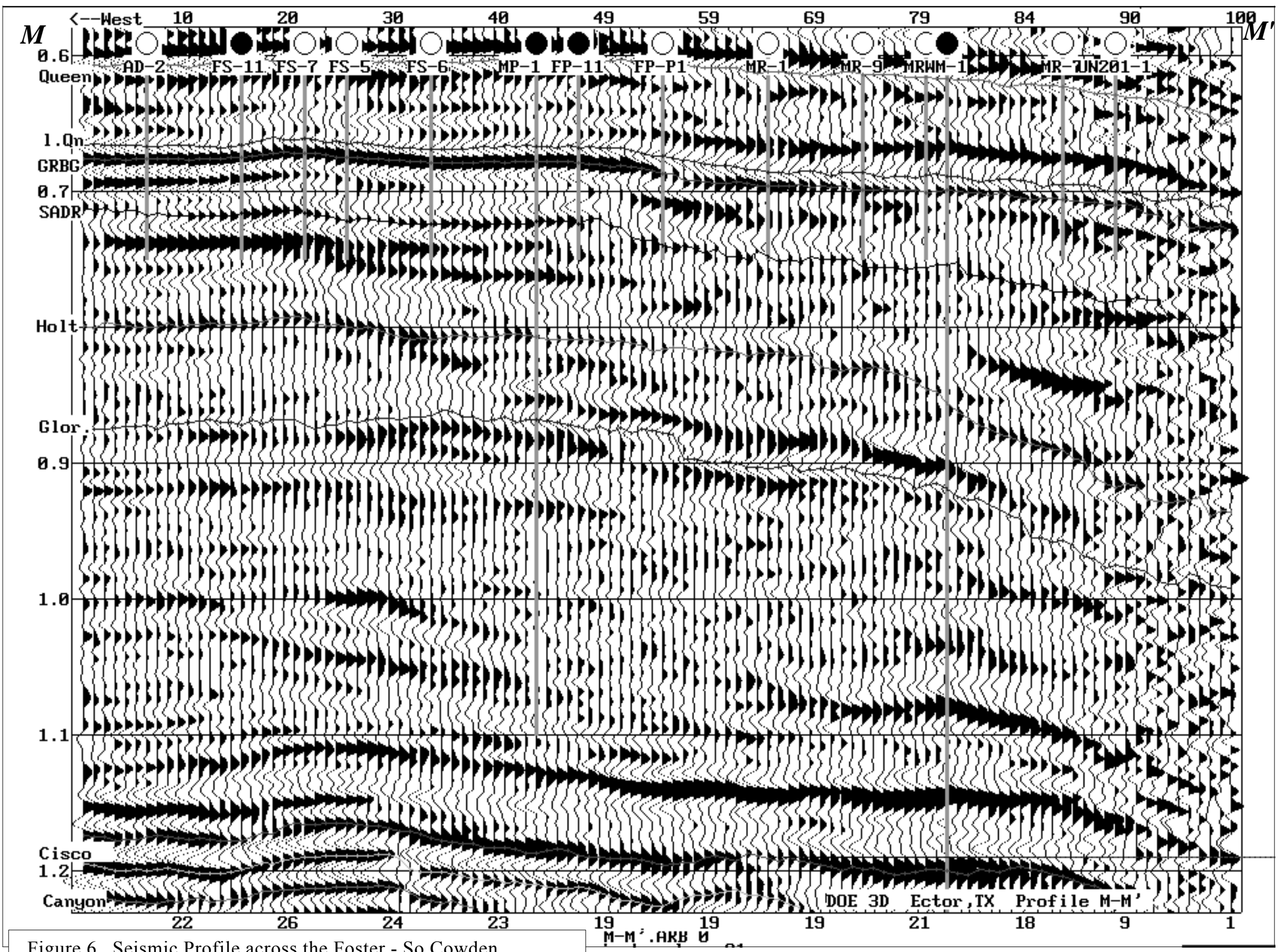

Figure 6. Seismic Profile across the Foster - So.Cowden

3D seismic survey, showing some structural and

stratigraphic features of the project. 

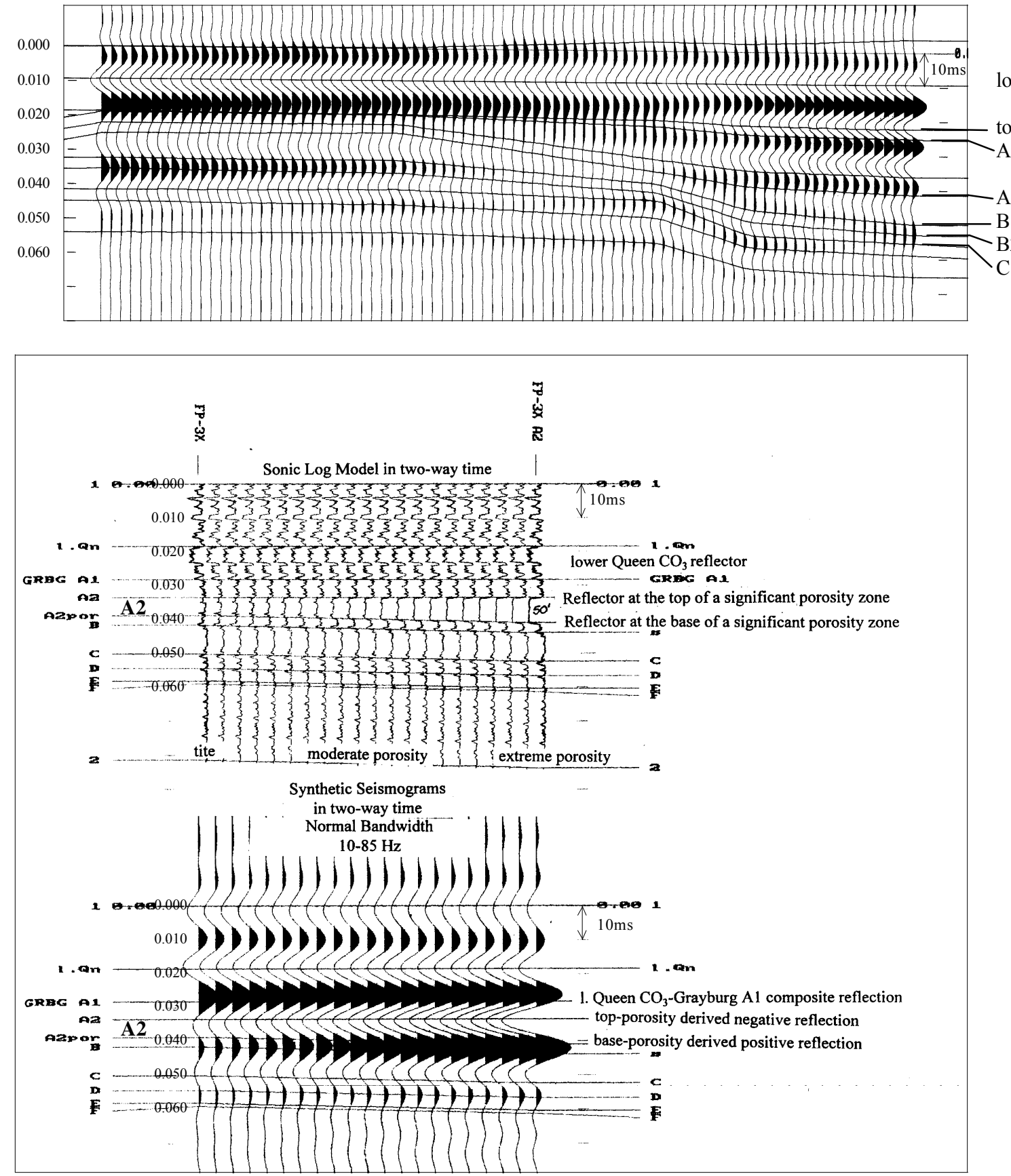

lower Queen sand top of Grayburg

Figure 7 . A seismic forward model made of synthetic seismograms generated from well sonic logs and interpolated logs. These traces represent the expected changes of seismic data character due to geologic variations across the survey discussed in this report.

Figure 8 . A seismic forward model similar to Fig. 7, but changes are made to only a single sonic log. The amount of porosity in the A2 zone is varied from very low (left) to very high (right). The purpose is to create a significant pair of impedance contrasts, at the top and the base of the modeled porous unit. The seismic response is a trough, then peak reflection having increased strength with increased porosity. 


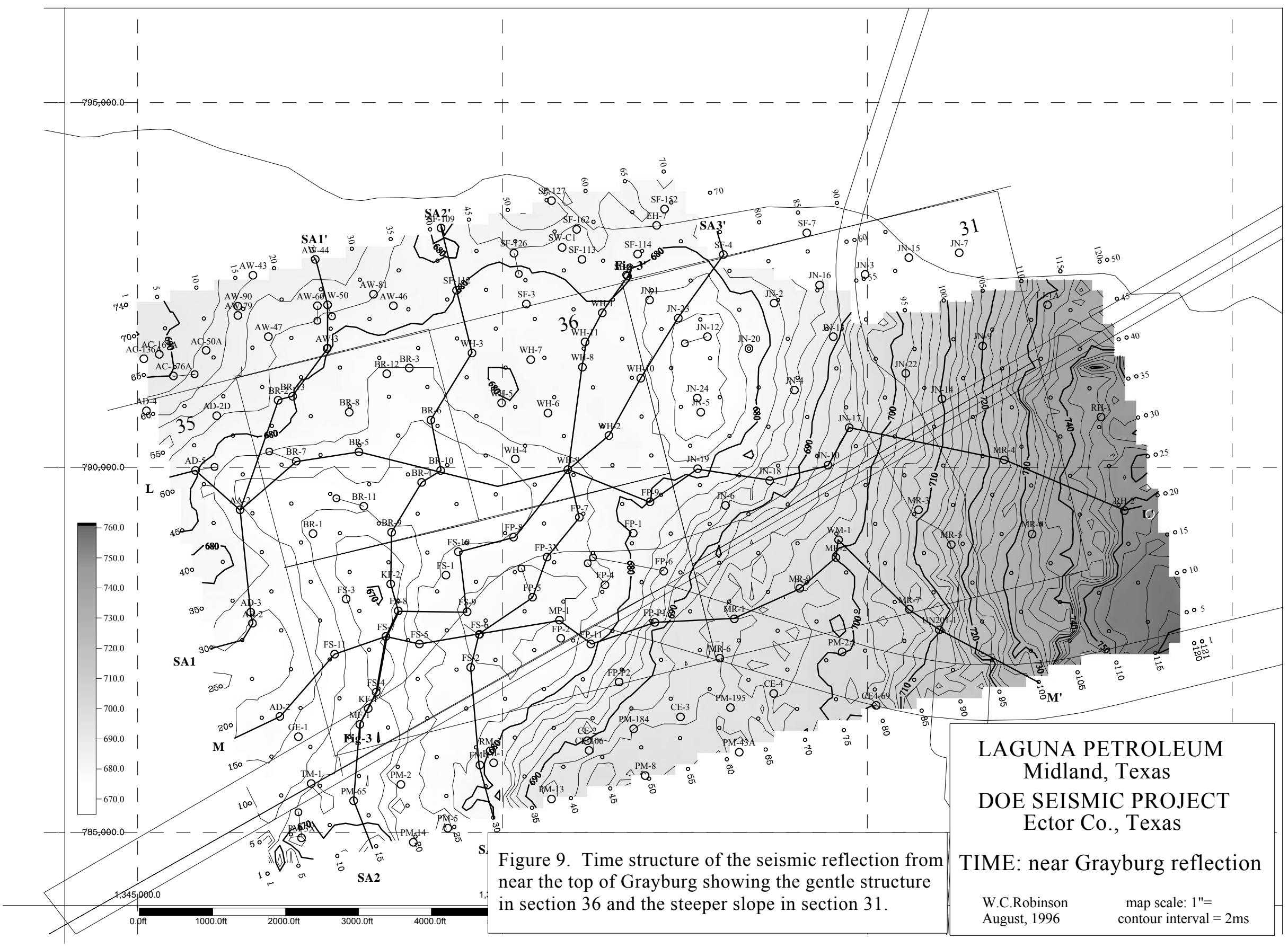




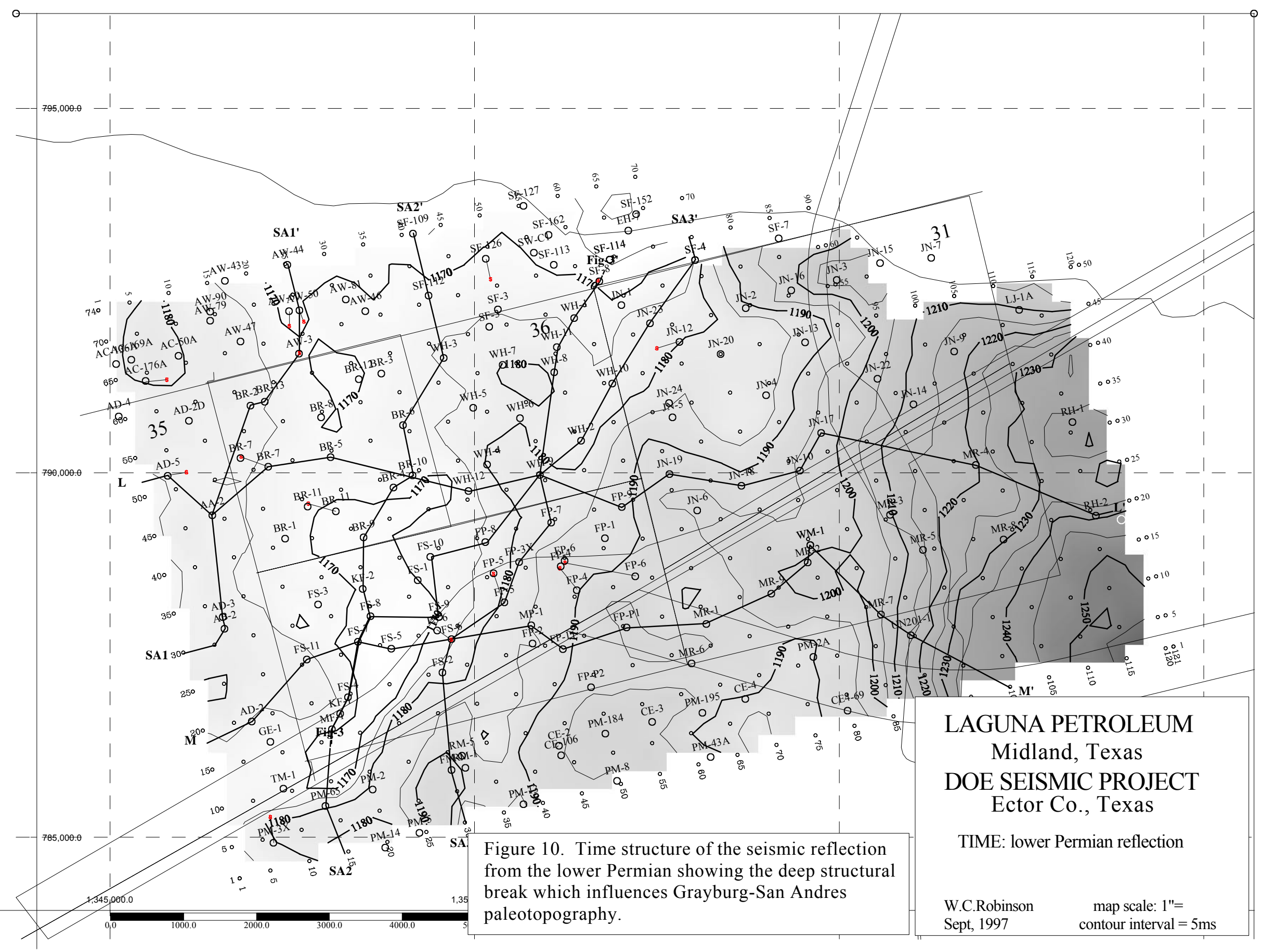




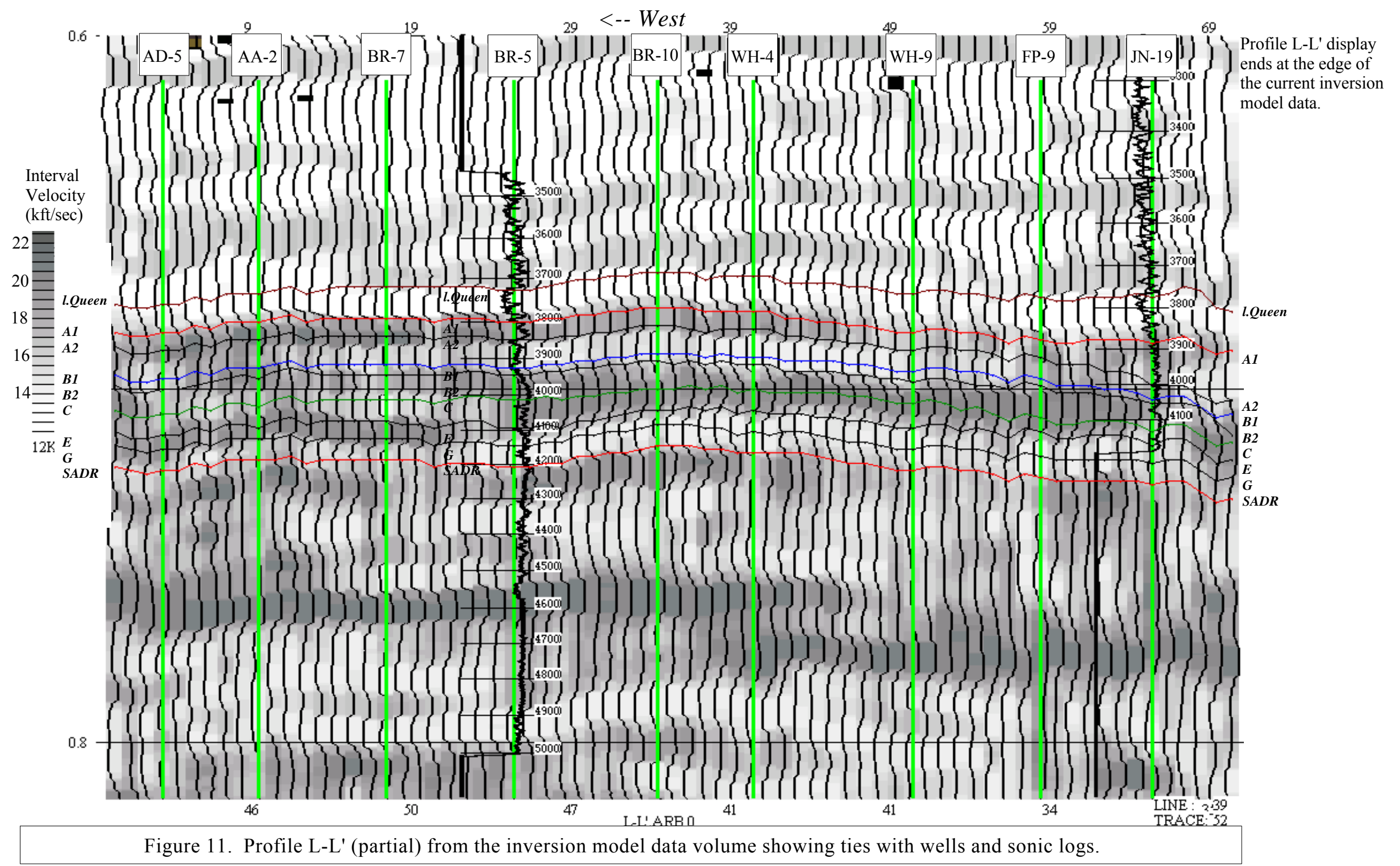




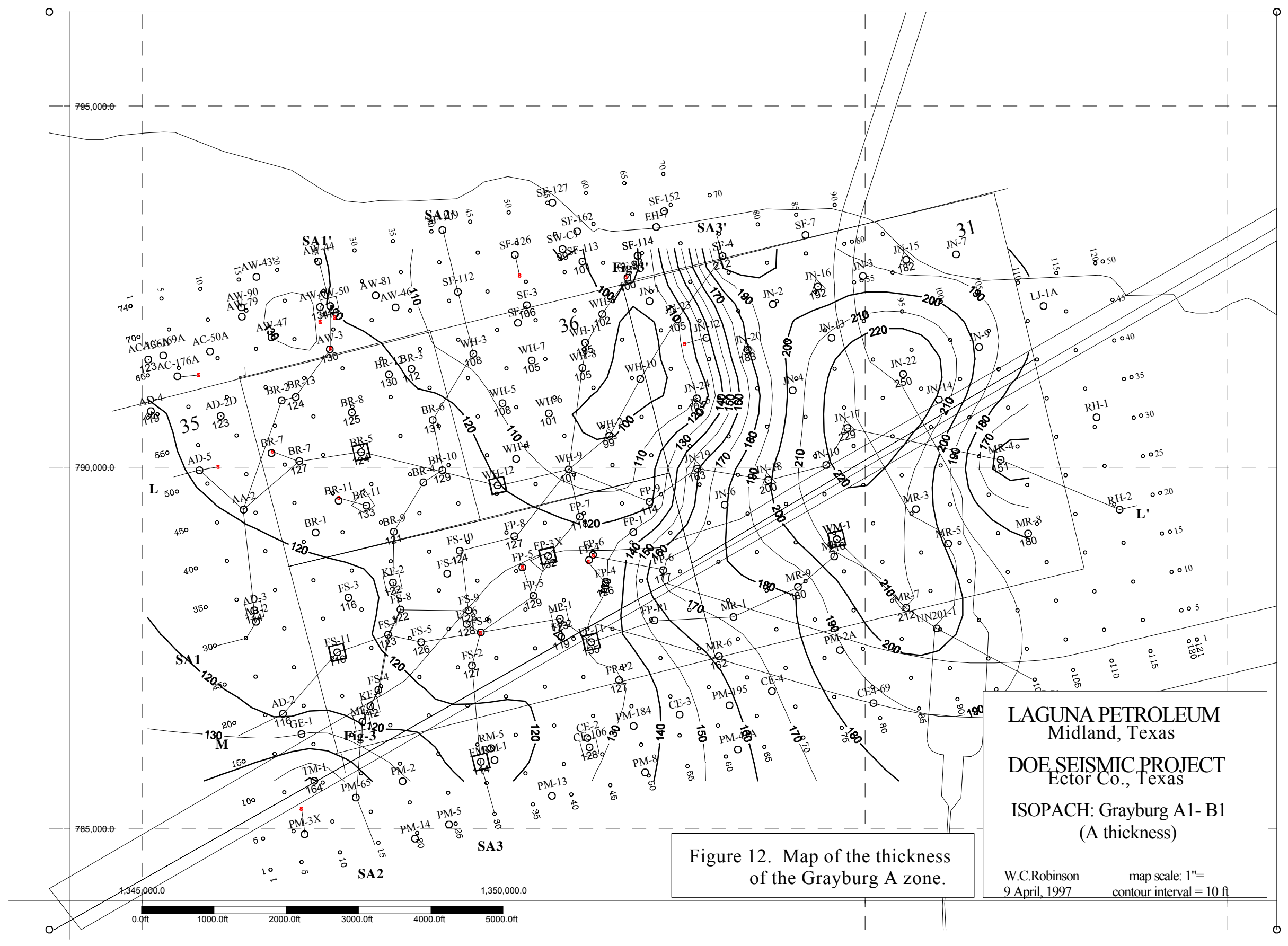




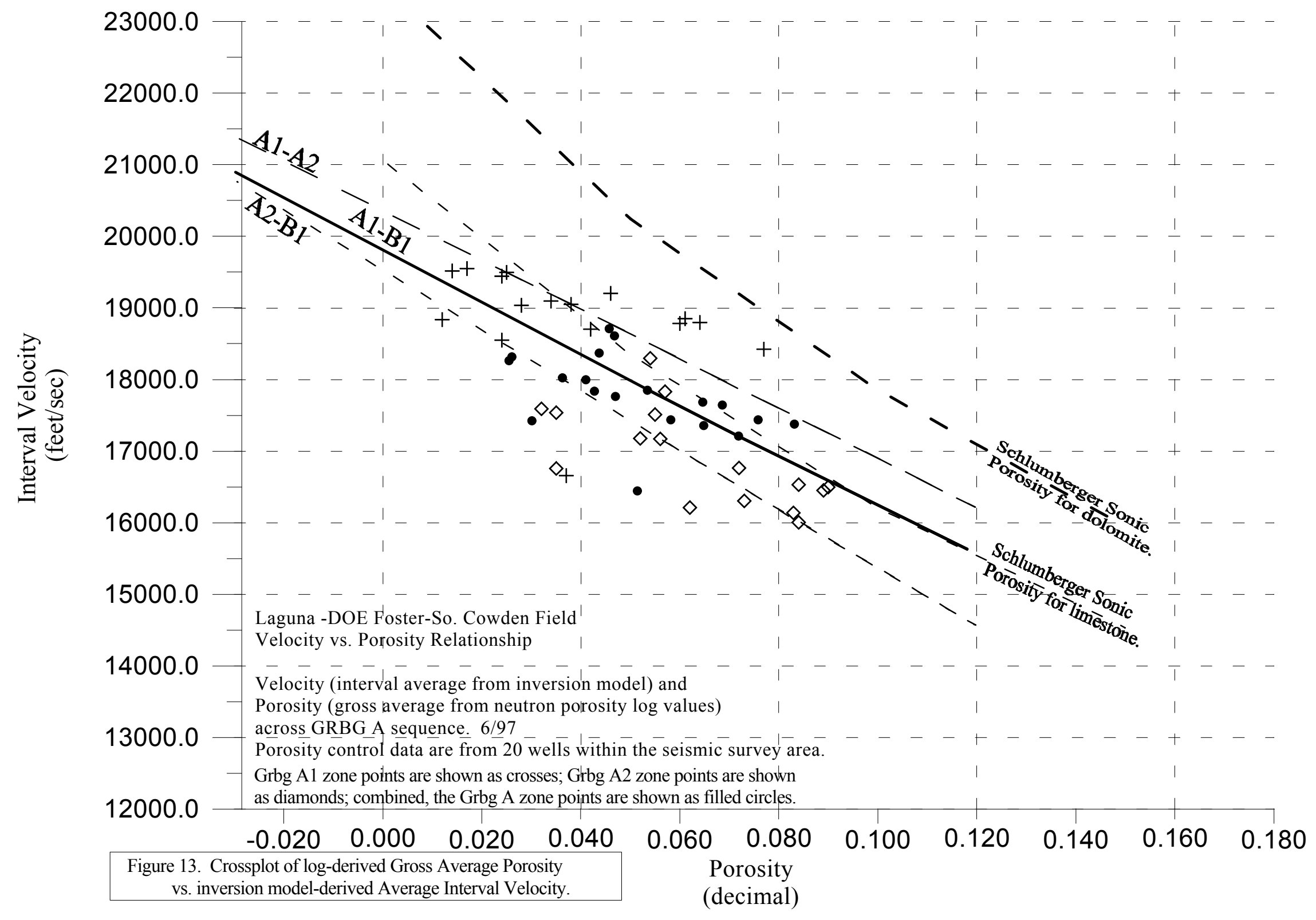




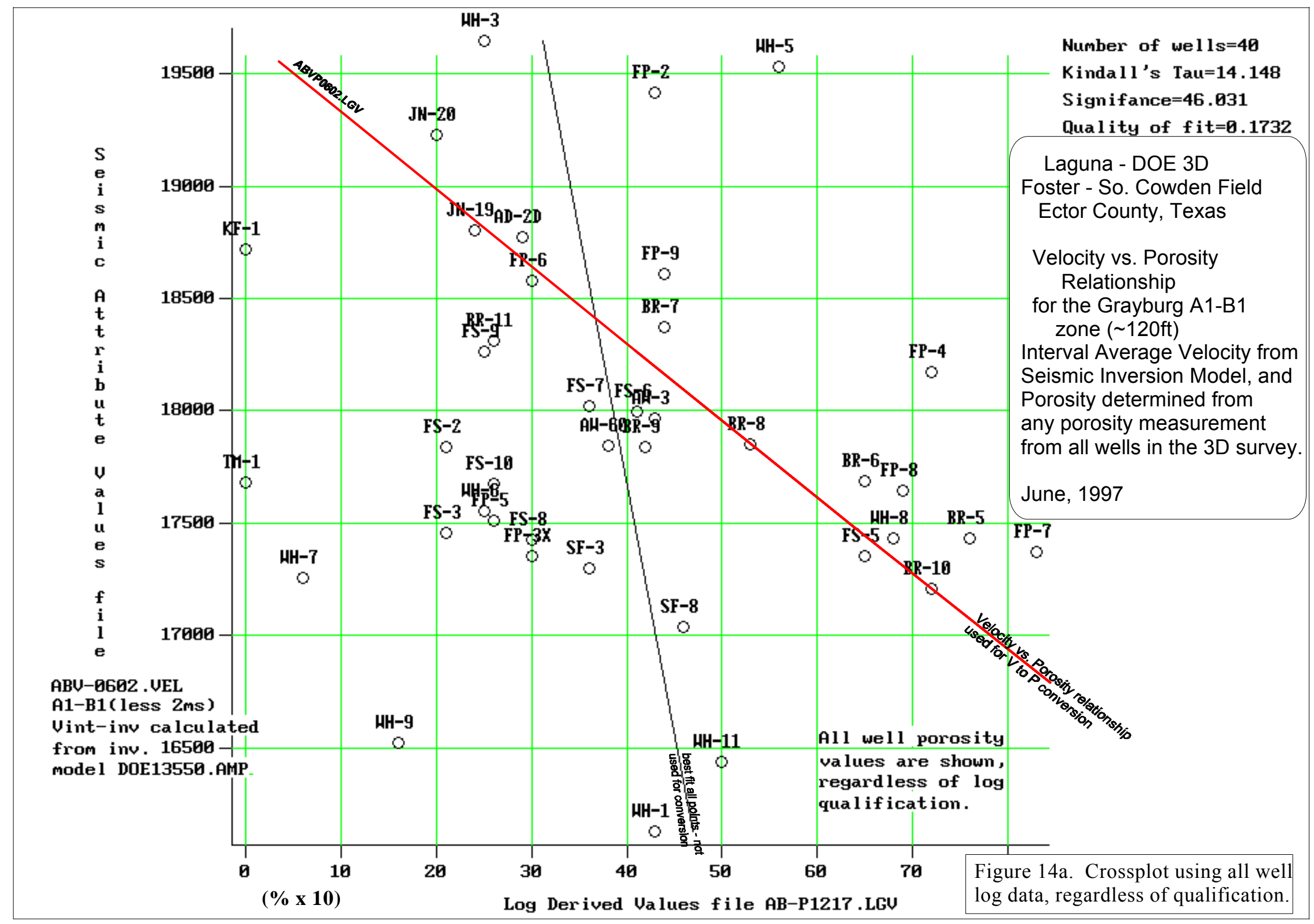




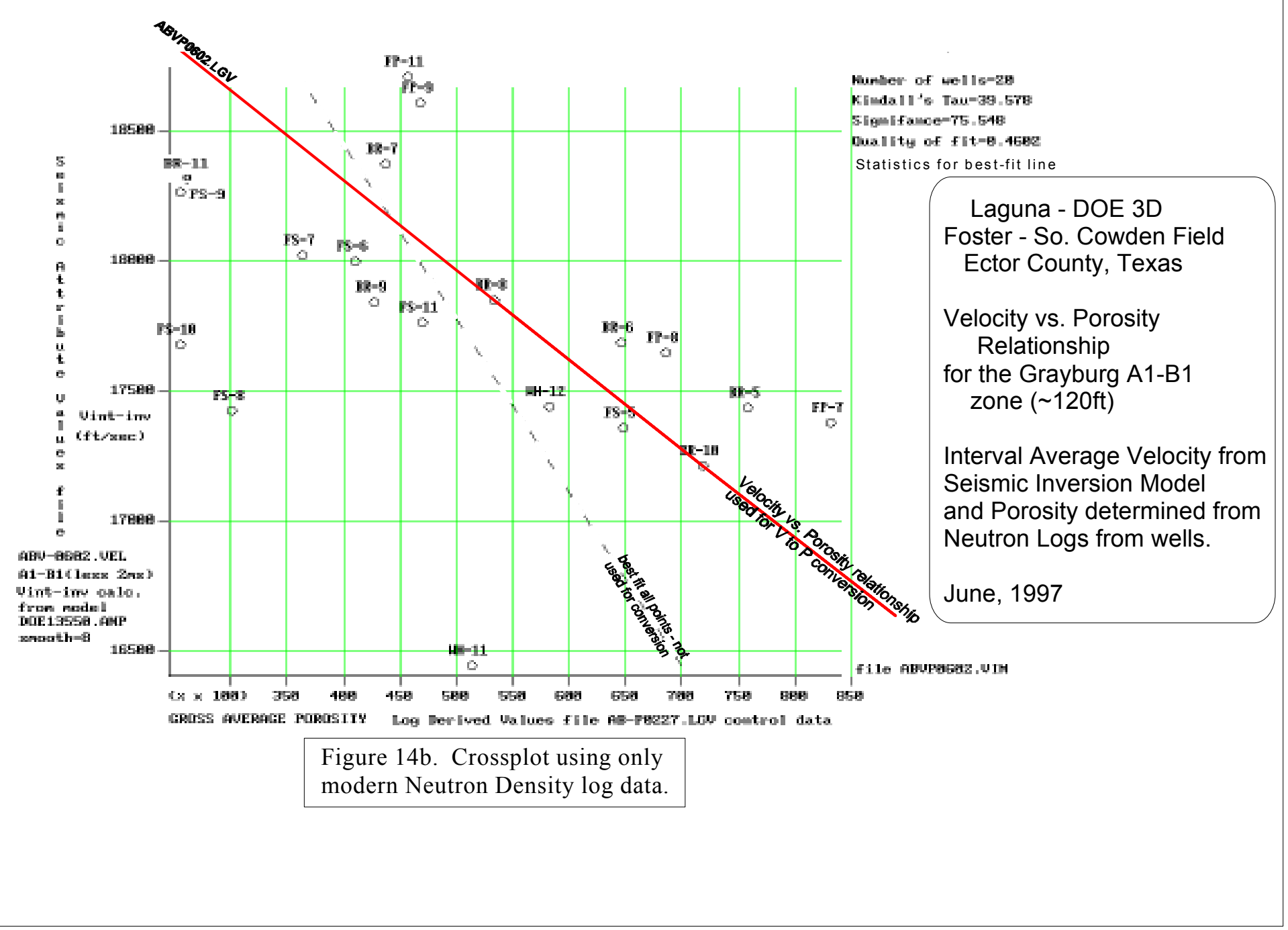




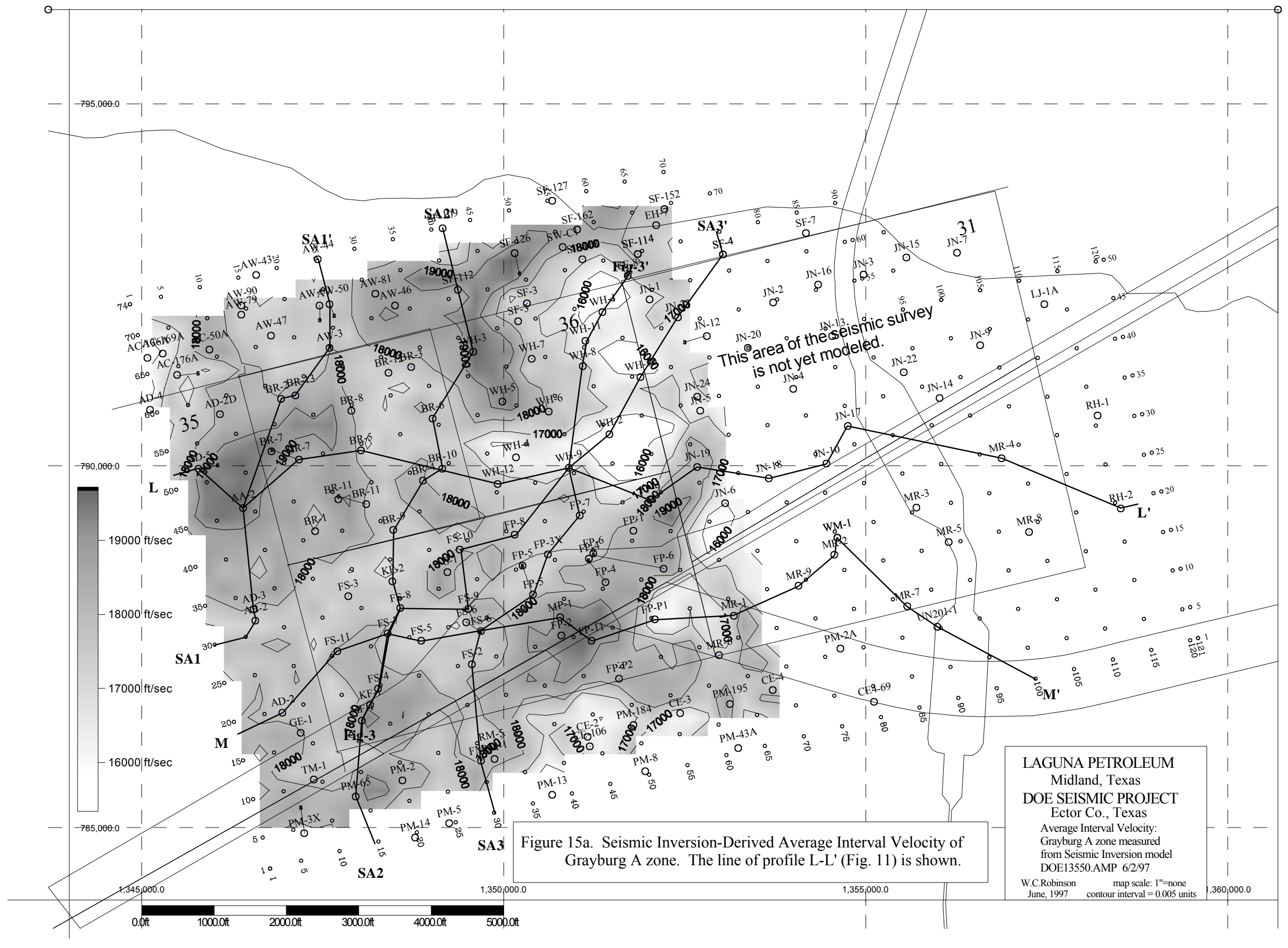




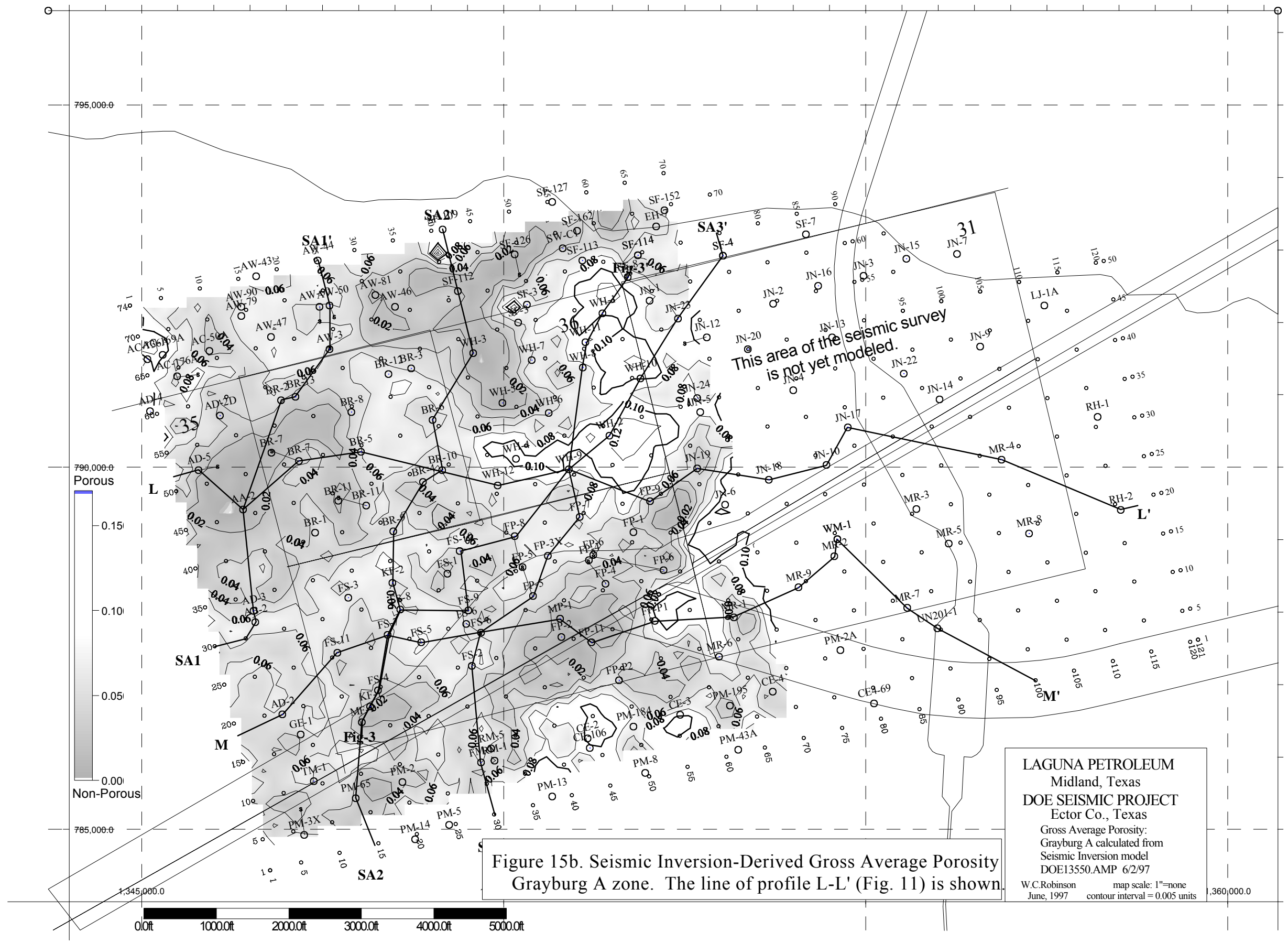




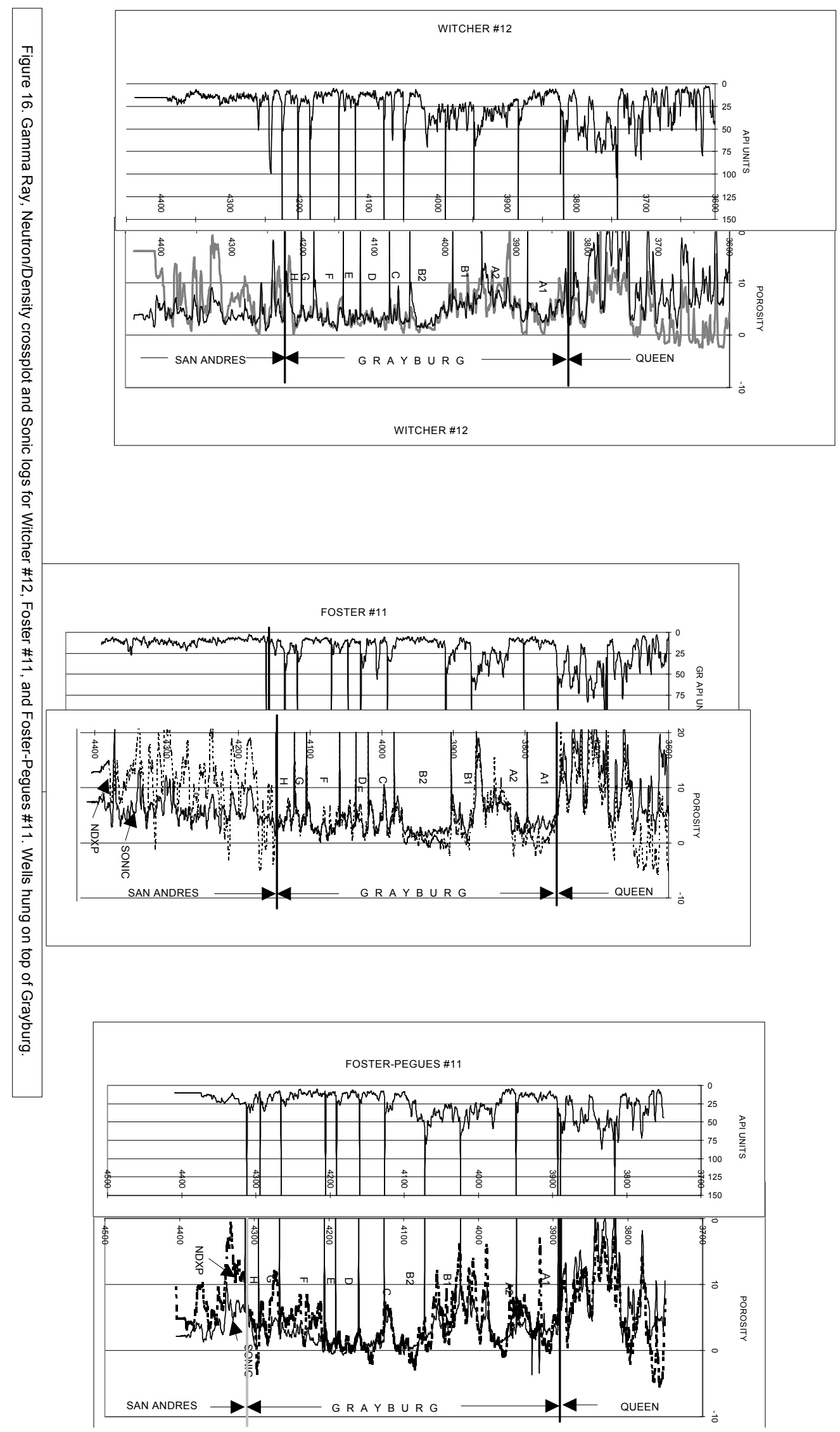




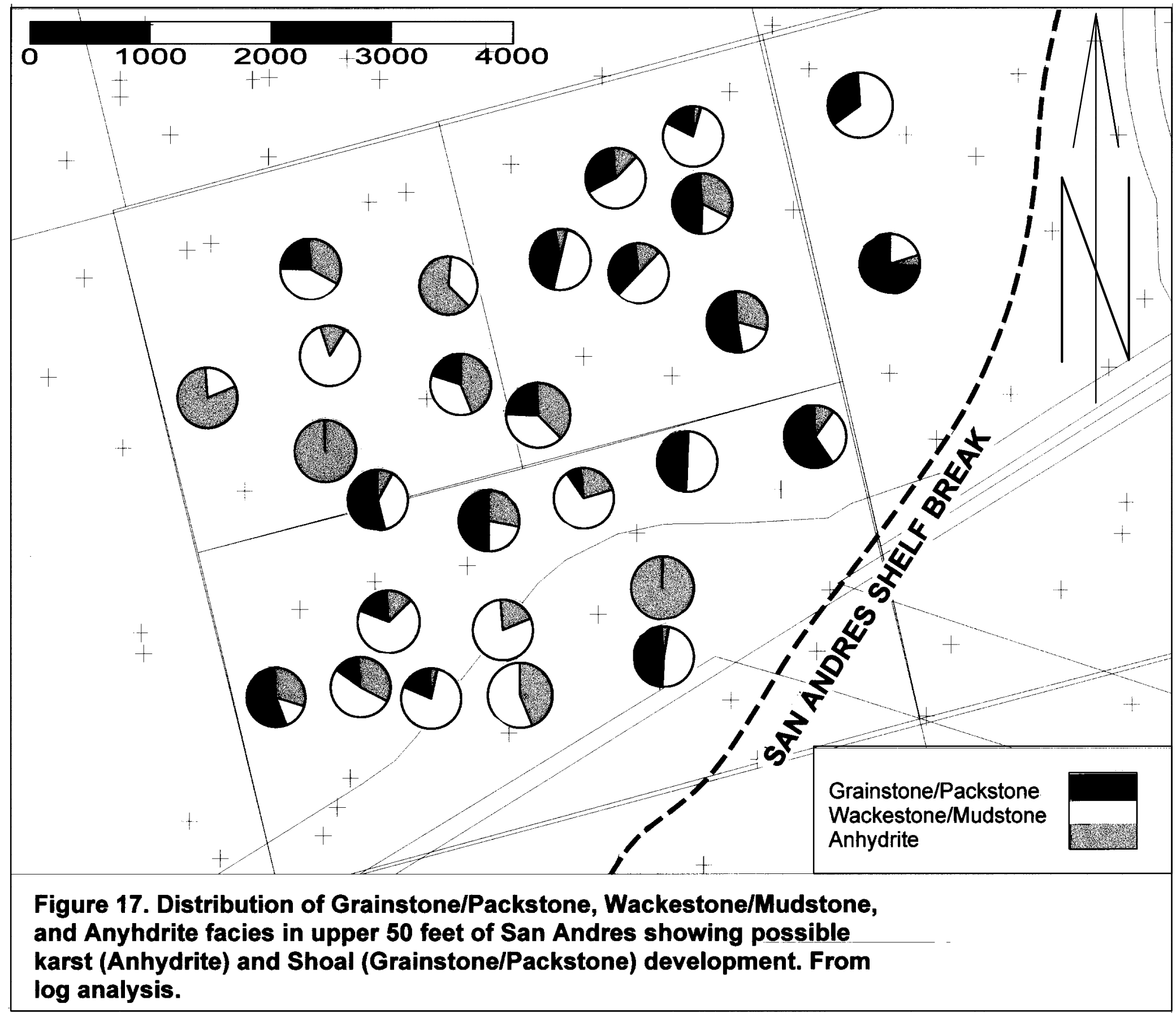




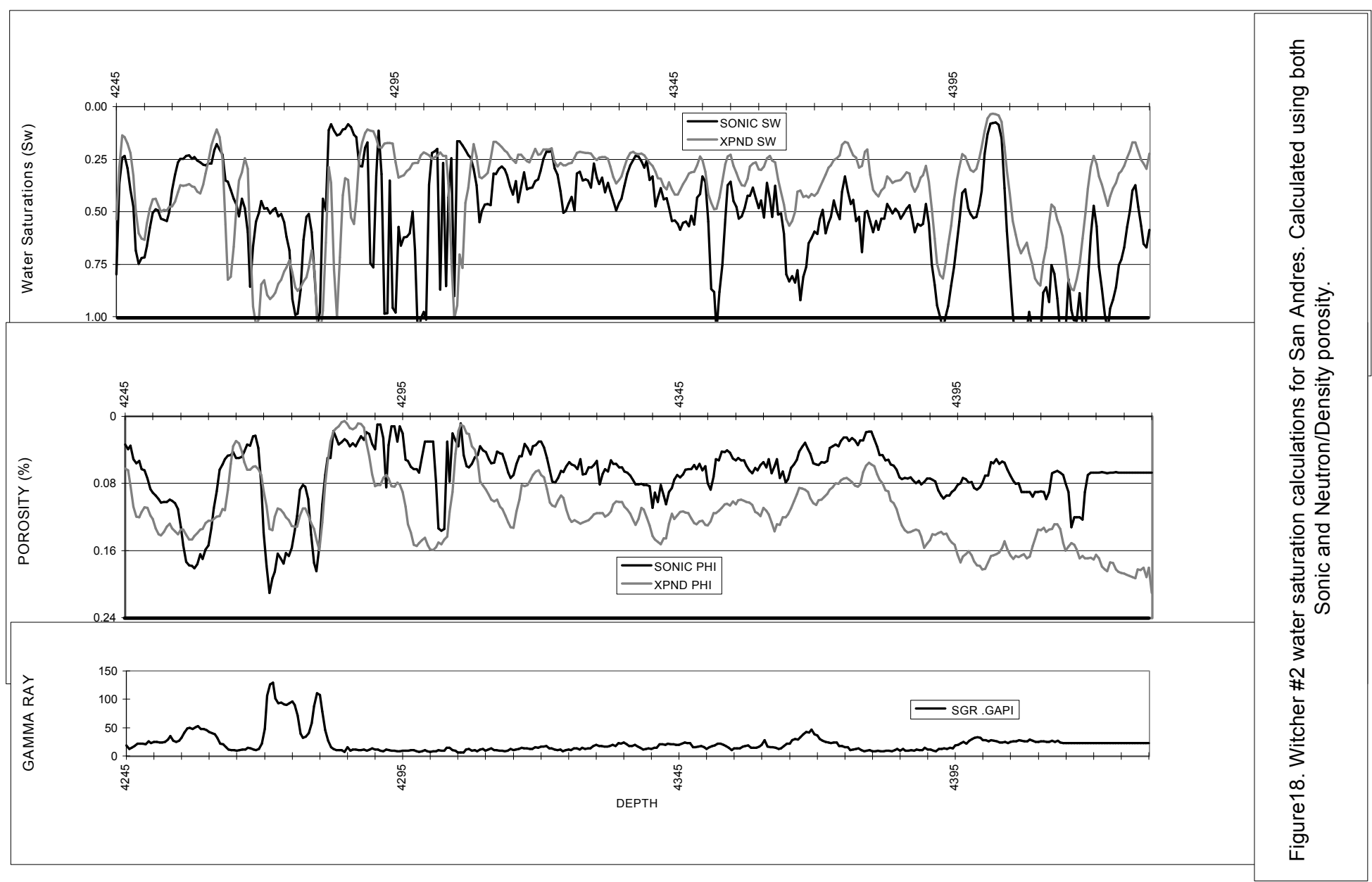




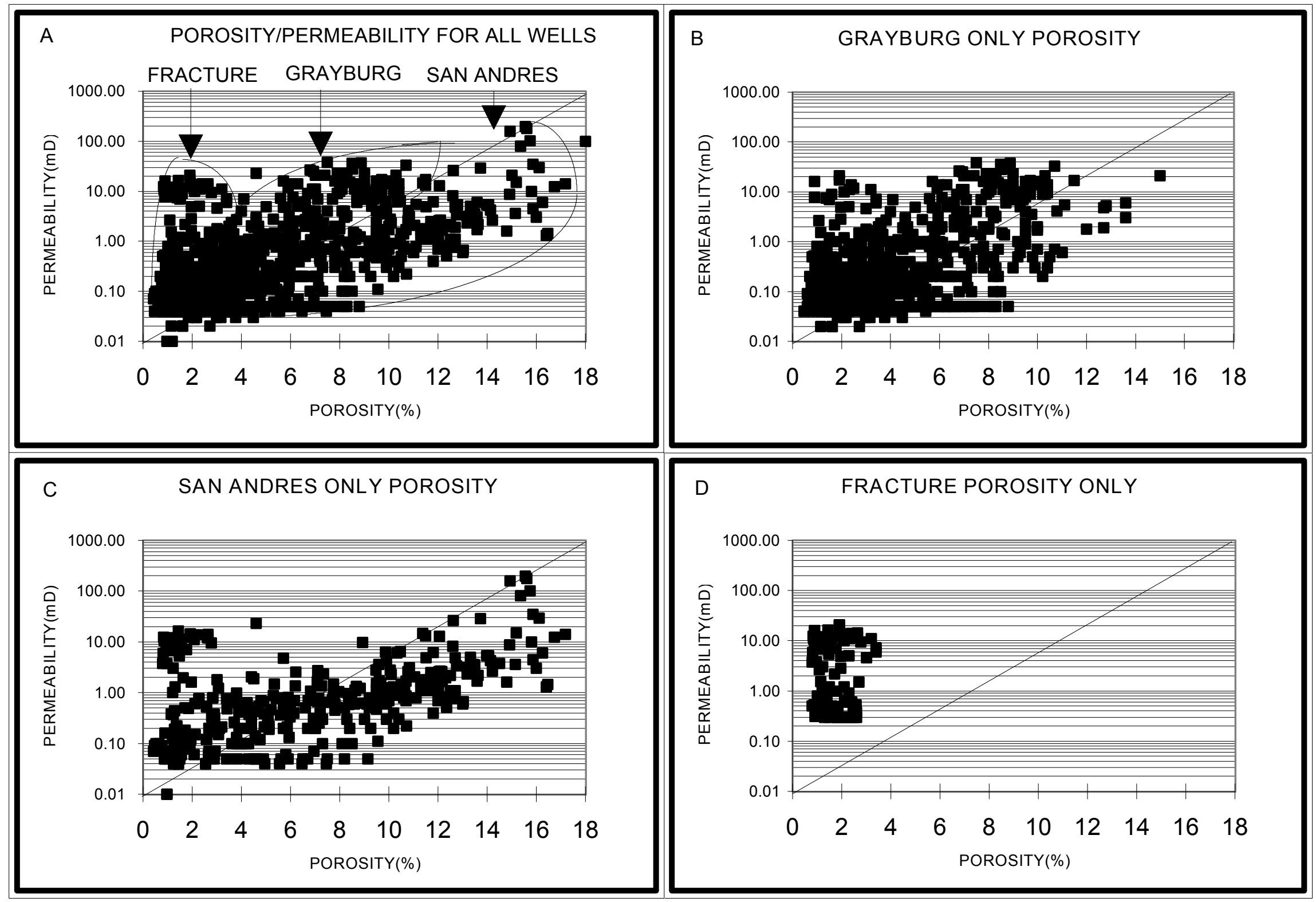

Figure 19. All core data in study area. (A) Primary, Secondary, and Fracture porosity fields. (B) Grayburg only porosity/permeabilities. (C) San Andres only porosity/permeabilities. (D) Fracture porosity. 


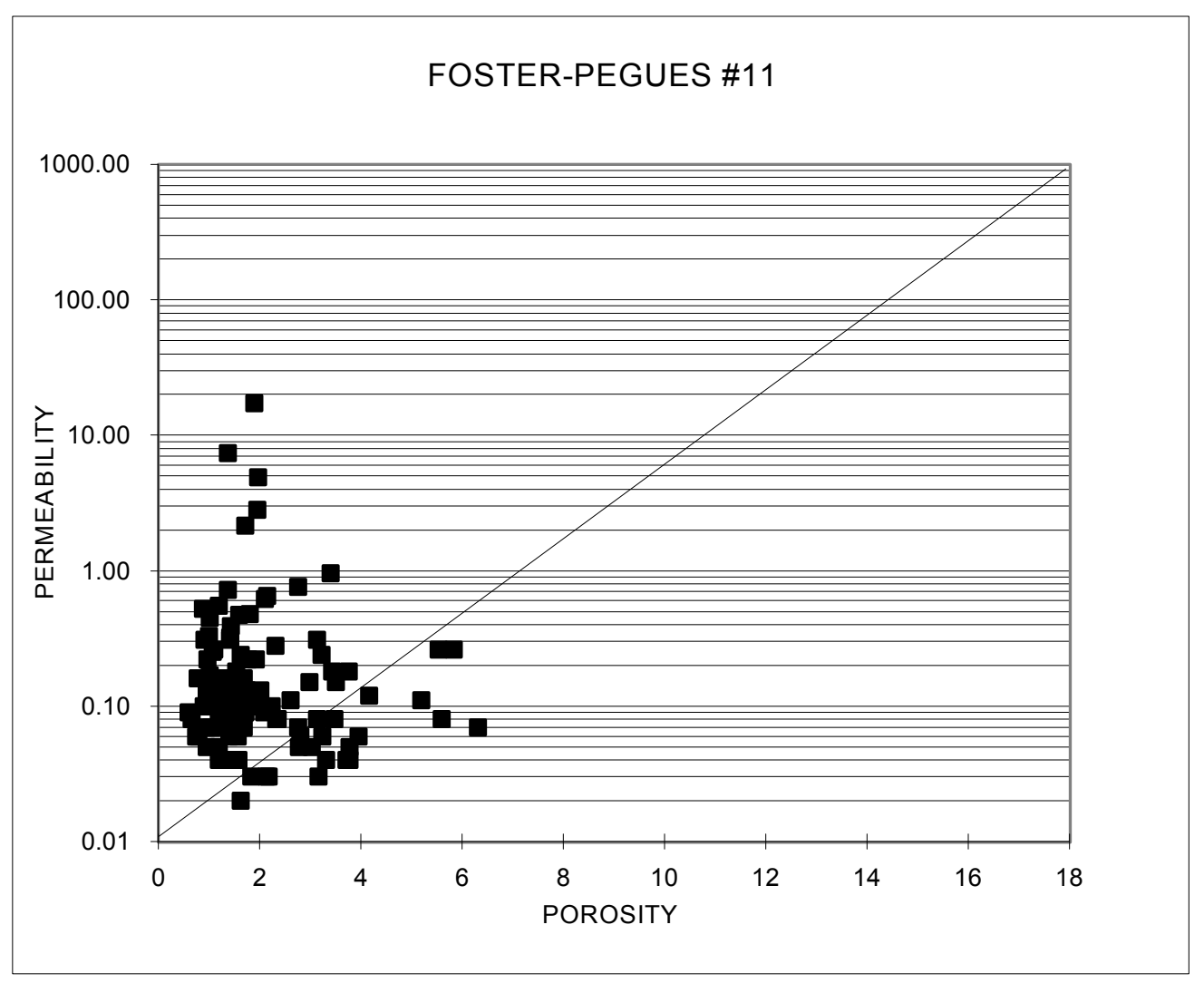

Figure 20. Core analyses for Foster-Pegues \#11, demonstrating low porosity and permeability in C, D, E, and F Zones. 


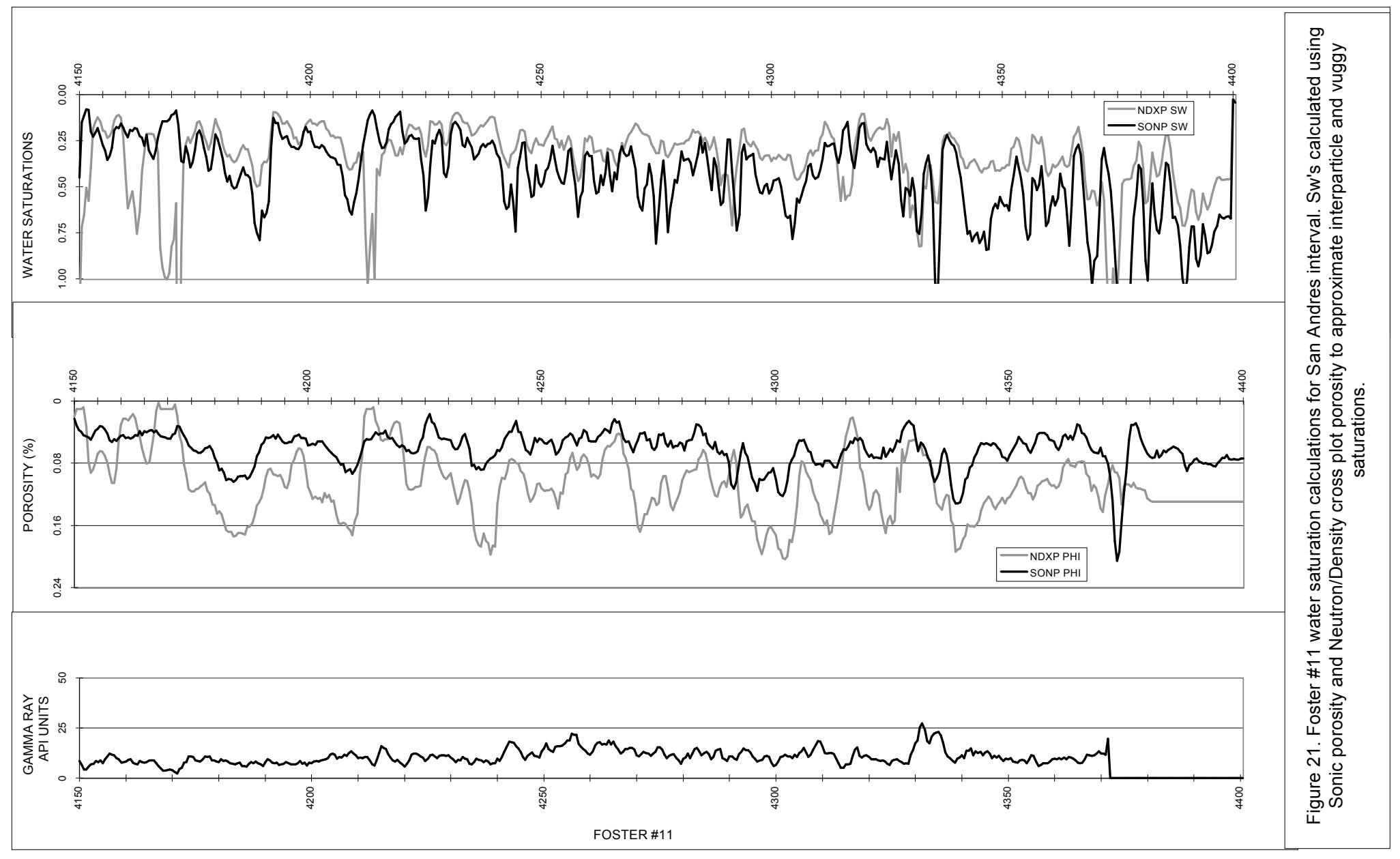



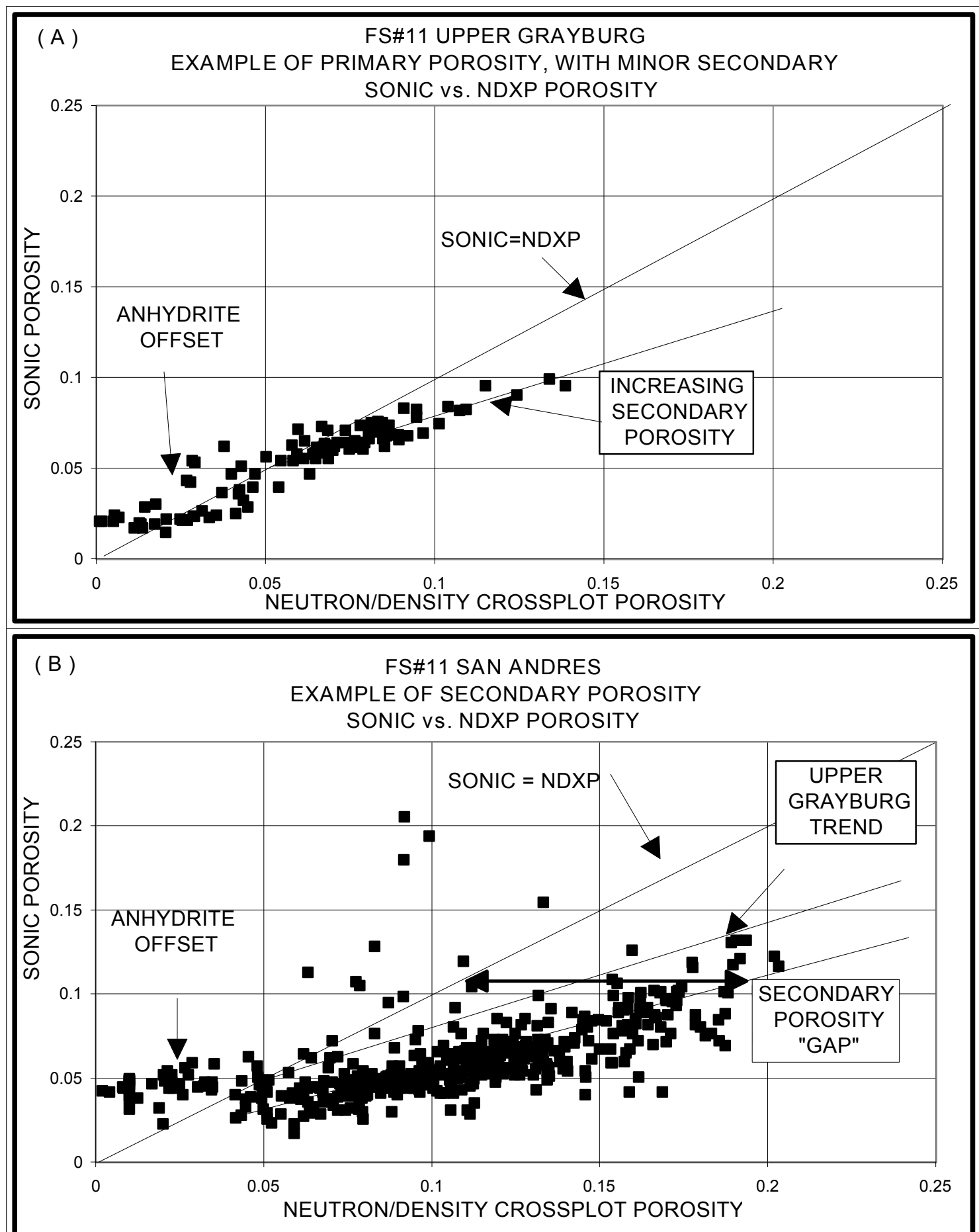

Figure 22. Cross-plot of Sonic vs. Neutron/Density porosity for Foster \#11. Upper Grayburg (A) showing primary porosity with little secondary porosity, and San Andres (B) with mostly secondary porosity. 


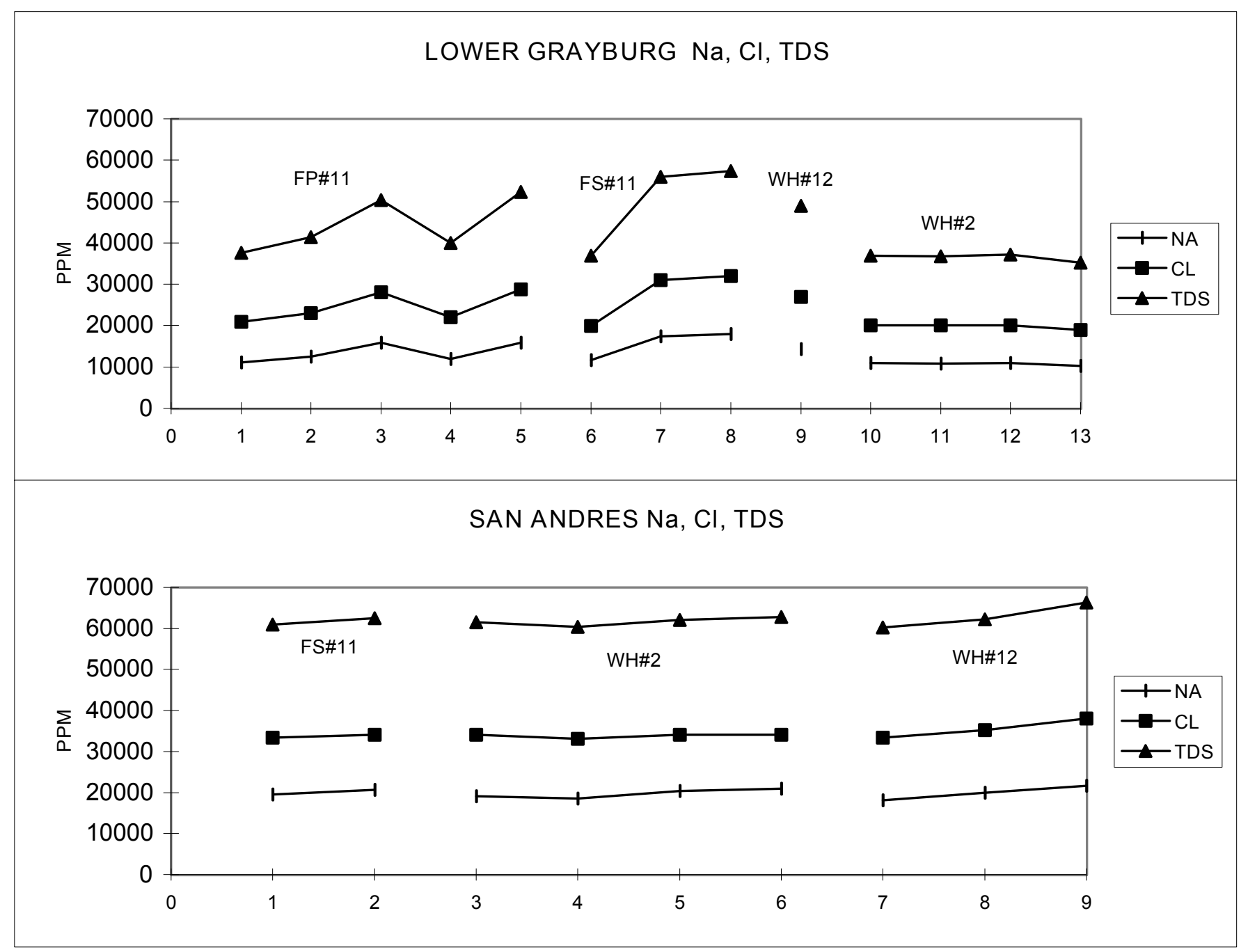

Figure 23. Analyses of produced waters from recently completed wells.

(A) lower Grayburg or mixed producers, (B) San Andres producers. 


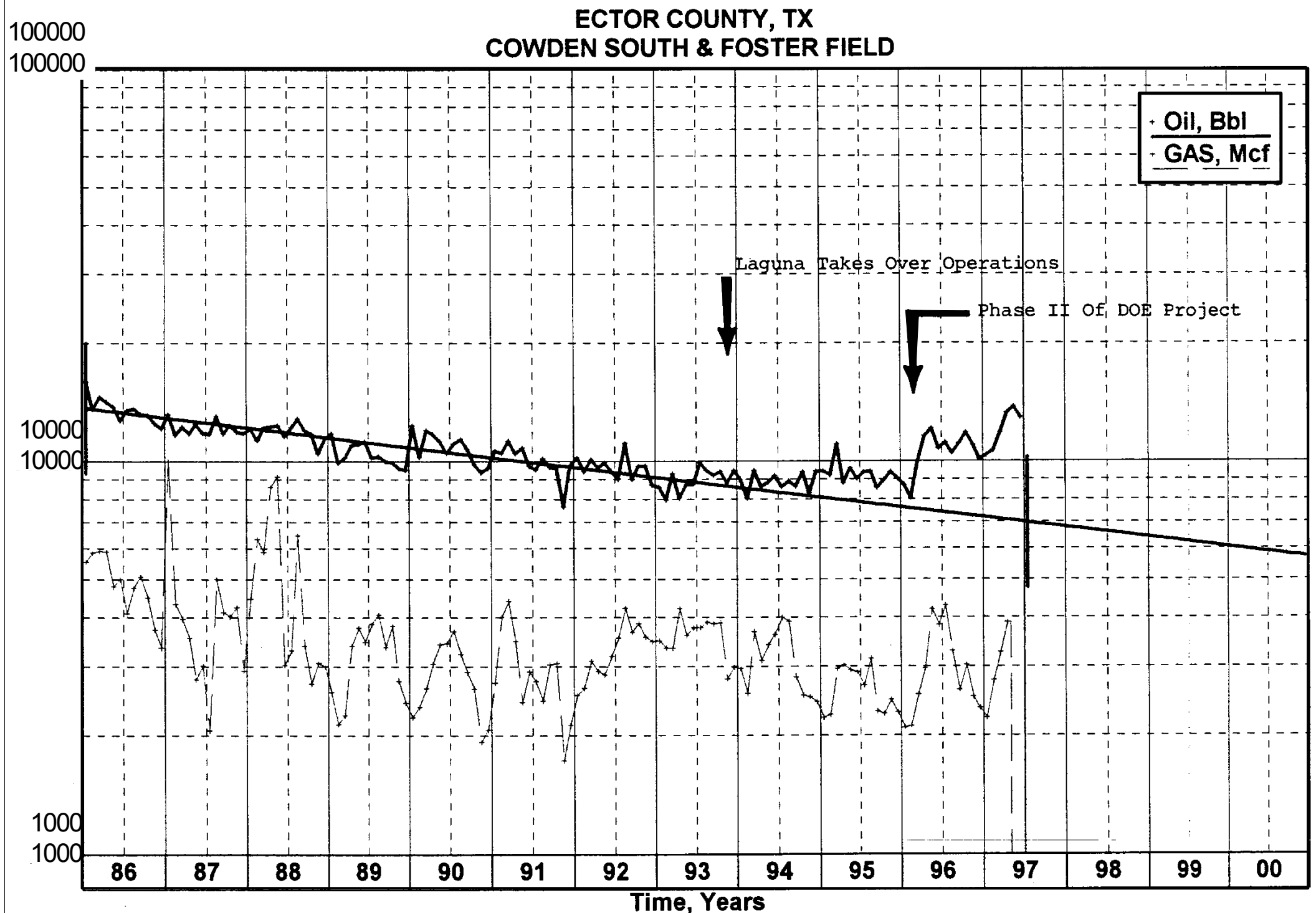

Figure 24. Section 36 production from 1986 to present, showing decline and impact of project recommendations. 